\title{
Stability Analysis of a Tapered Symmetric Sandwich Beam Resting on a Variable Pasternak Foundation
}

\author{
Madhusmita Pradhan, P. R. Dash, Mrunal Kanti Mishra and Prasanta Kumar Pradhan \\ Department of Mechanical Engineering, VSSUT, Burla, India, 768018.
}

\begin{abstract}
(Received 9 December 2015; accepted 28 June 2016)
The static and dynamic stability analysis of a three-layered, tapered and symmetric sandwich beam resting on a variable Pasternak foundation and undergoing a periodic axial load has been carried out for two different boundary conditions by using a computational method. The governing equation of motion has been derived by using Hamilton's principle along with generalized Galerkin's method. The effects of elastic foundation parameter, core-loss factor, the ratio of length of the beam to the thickness of the elastic layer, the ratio of thickness of shear-layer of Pasternak foundation to the length of the beam, different modulus ratios, taper parameter, core thickness parameter, core-density parameter and geometric parameter on the non-dimensional static buckling load and on the regions of parametric instability are studied. This type of study will help the designers to achieve a system with high strength to weight ratio and better stability which are the desirable parameters for many modern engineering applications, such as in the attitude stability of spinning satellites, stability of helicopter components, stability of space vehicles etc.
\end{abstract}

\section{NOMENCLATURE}

\begin{tabular}{|c|c|}
\hline$A_{f}$ & Areas of cross section of a face layer, \\
\hline$B$ & Width of beam, \\
\hline$E_{f}$ & Young's modulus of face layers, \\
\hline$G_{S}$ & $\begin{array}{l}\text { Modulus of the shear layer of a Pasternak } \\
\text { foundation, }\end{array}$ \\
\hline$G_{S} / E_{f}$ & $\begin{array}{l}\text { The ratio of modulus of the shear layer of } \\
\text { a Pasternak foundation to Young's modulus } \\
\text { of the elastic layer, }\end{array}$ \\
\hline$G_{2}^{*}$ & $G_{2}(1+j \eta)$, complex shear modulus of core, \\
\hline$G_{2} / E_{f}$ & $\begin{array}{l}\text { The ratio of in-phase shear modulus of the } \\
\text { viscoelastic core to Young's modulus of the } \\
\text { elastic layer, }\end{array}$ \\
\hline$g^{*}$ & $\mathrm{~g}(1+j \eta)$, complex shear parameter, \\
\hline$g$ & Shear parameter, \\
\hline$I_{f}$ & $\begin{array}{l}\text { Second moments of the area of cross section } \\
\text { about a relevant axis of face layer, }\end{array}$ \\
\hline$l$ & Beam length, \\
\hline$l_{h_{f_{0}}}$ & $l / h_{f_{0}}$ \\
\hline $\bar{m}$ & Mass/unit length of beam, \\
\hline$\overline{P_{1}}$ & $\begin{array}{l}\text { Nondimensional amplitude for the } \\
\text { dynamic loading, }\end{array}$ \\
\hline$t$ & Time, \\
\hline $\bar{t}$ & Nondimensional time, \\
\hline$u(x, t), U_{1}(x, t)$ & $\begin{array}{l}\text { Axial displacement at the middle of } \\
\text { the top layer of a beam, }\end{array}$ \\
\hline$w(x, t)$ & Transverse deflection of a beam, \\
\hline$w^{\prime}$ & $\frac{\partial w}{\partial x}$ \\
\hline$w "$ & $\frac{\partial^{2} w}{\partial x^{2}}$ \\
\hline$Y$ & Geometric parameter, \\
\hline $\bar{w}, \overline{t t}$ & $\frac{\partial^{2} \bar{w}}{\partial \overline{-n}^{2}}$ \\
\hline$U_{i, x}$ & $\frac{\partial U_{i}}{\partial x}($ here, $i=1,3)$ \\
\hline$\delta$ & $\begin{array}{l}\text { Thickness of the shear layer of } \\
\text { a Pasternak foundation, }\end{array}$ \\
\hline
\end{tabular}

$\rho_{f}$ Density of face layers,

$\rho_{c} \quad$ Density of the core layer,

$\omega$ Frequency of the forcing function,

$\bar{\omega} \quad$ Nondimensional forcing frequency,

$\alpha$ Taper parameter,

$B$ Core thickness parameter,

$\mu$ Core density parameter.

\section{INTRODUCTION}

The study of the vibration and stability of sandwich beams has attained great importance with their use in space vehicles, aeroplanes, military aircraft, and ships as a load-carrying member with a high strength-to-weight ratio. In mechanical engineering, there are many applications for beams on elastic foundations. An extensive study of stability analysis of beams on elastic foundations has been carried out by a number of investigators. The concept was discussed in detail by Heteny. ${ }^{1}$ The frequency response curves of a non-uniform beam undergoing nonlinear oscillations analytically by the multiple time scale method were determined by Clementi et al. ${ }^{2}$ Chonan studied the vibration and stability of sandwich beams with elastic ${ }^{3}$ and imperfect ${ }^{4}$ bonding under conservative and non-conservative axial forces. Asani and Nakra investigated the vibration damping characteristics ${ }^{5,6}$ and performed forced vibration analysis $^{7}$ of multi-layered beams with viscoelastic cores. The primary resonance of forced and undamped bending vibrations of a non-uniform beam with constant width, rectangular crosssection, and convex parabolic thickness variation were investigated by Caruntu. ${ }^{8}$ Kar and Sujata ${ }^{9}$ studied the dynamic stability of a tapered symmetric sandwich beam under a pulsating axial force and obtained the parametric instability regions. The effect of shear parameter, core thickness, and core loss factors on regions of parametric instability of sandwich beams with viscoelastic cores for various boundary conditions were investigated by Ray and Kar. ${ }^{10}$ The same authors studied the para- 
metric instability of multi-layered symmetric sandwich beams with alternate elastic and viscoelastic layers subjected to a periodic axial load. ${ }^{11} \mathrm{Rao}^{12}$ derived a sixth-order differential equation of motion by using the energy method for sandwich beams under various boundary conditions using the classical sandwich beam theory. A general analysis of damping by a damping constrained viscoelastic layer was presented by Kerwin. ${ }^{13}$ The response of viscoelastically supported beams was studied by Saito and Otomi. ${ }^{14}$ The mathematical hypothesis that a beam on equidistant elastic supports can be considered as a beam on an elastic foundation in static and free vibration problems was presented by Sato et al. ${ }^{15}$ The nonlinear vibration and parametric instability of the inextensional beam on an elastic foundation was investigated by Wang et al. ${ }^{16}$ Again, Wang et al. ${ }^{17}$ obtained the nonlinear equation of motion of a beam on an elastic foundation by using Newton's second law of motion. The multi-frequency excitation of a magnetorheological elastomer-based sandwich beam with conductive skins was carried out by Nayak et al. ${ }^{18}$ The same authors studied the dynamic stability of a magnetorheological elastomerbased adaptive sandwich beam with conductive skins. ${ }^{19}$ Lenci and Clementi ${ }^{20}$ studied the linear dynamics of a two-layered beam considering the effects of shear stiffness, rotary and axial inertia, and interface stiffness. The same authors obtained the natural frequencies of a two-layered beam with an elastic interface. ${ }^{21}$ The stability of an asymmetric sandwich beam resting on a Pasternak foundation was investigated by Dash et al. $^{22}$ Lenci et al. ${ }^{23}$ investigated the nonlinear free vibration of a two-layered elastic composite beam, both symmetric and non-symmetric with respect to the beam midpoint. The approximate analytical expressions for the natural frequencies of non-uniform cables and beams by using the asymptotic development method was obtained by the same authors. ${ }^{24}$ Babilio $^{25}$ investigated the dynamics of a simply supported beam made of an axially functionally graded material under an axial timedependent load. $\mathrm{Ko}^{26}$ investigated the flexural behaviour of a rotating non-symmetric tapered sandwich beam under uniformly and linearly distributed loads. The damping effectiveness of clamped-free and hinged-hinged tapered symmetric sandwich beams was studied by Rao and Stuhler. ${ }^{27}$ Ahuja and Duffield ${ }^{28}$ obtained theoretical and experimental results for the steady-state response and the instability boundaries of a variable cross-section beam on an elastic foundation. Szekremyes $^{29}$ examined the free vibration of delaminated composite beams.

From the available literature, it is seen that some works have been carried out on the stability of a sandwich beam resting on a Pasternak foundation. Also it is seen that taper parameter, elastic foundation parameter, and viscoelastic core affect the stability of the system. But a study of a tapered symmetric sandwich beam resting on a variable Pasternak foundation subjected to parametric vibration has not been done before now. As the combination of the above parameters may develop an economical system with high strength-to-weight ratio and better stability, which will be suitable for the base foundations of multi-storied buildings in earthquake prone areas, heavy machinery, and aerospace applications, this study has importance. By making the sandwich beam taper and using the suitable stiffness value for the spring, material can be saved and simultaneously the strength can be increased. This is desirable for the designer, as strength and economy are important pa- rameters for the design of any machine component. Hence, emphasis has been given in this research work to study the effect of the taper parameter and the spring stiffness parameter on the stability of the sandwich beam. The present work deals with the static and dynamic stability of a tapered symmetric sandwich beam with a viscoelastic core resting on a variable Pasternak foundation under two different boundary conditions. The effects of the geometric parameter, core loss factor, modulus ratios, and shear parameters on the nondimensional static buckling loads and regions of parametric instability are examined by computational methods, and the results are presented graphically.

\section{FORMULATION OF THE PROBLEM}

Figure 1 shows a tapered symmetric sandwich beam of length $l$ resting on a variable Pasternak foundation subjected to a pulsating axial force $P(t)=P_{0}+P_{1} \cos (\omega t)$ acting along its un-deformed axis at one end. $P_{0}$ and $P_{1}$ are respectively the static and dynamic load amplitudes. The face layers are made of an elastic material with thickness $\left(2 h_{f}\right)_{0}$ at one end and $\left(2 h_{f}\right)_{l}$ at the other with Young's modulus $E_{f}$. The core is made of a viscoelastic material with complex shear modulus $G_{2}^{*}=G_{2}(1+j \eta)$ and having thicknesses $\left(2 h_{c}\right)_{0}$ and $\left(2 h_{c}\right)_{l}$ at the ends. The foundation is comprised of equal and closely placed vertical springs with a variable spring constant $K(x)\left(N / m / m^{2}\right)$, supporting a shear layer of thickness $\delta$, with a shear modulus of $G_{S}$.

The following assumptions are made for deriving the equations of motion.

1. The beam transverse deflection is small, and is the same everywhere in a given cross section.

2. The metallic layer obeys the Euler-Bernoulli assumption of beam theory.

3. The layers are perfectly bonded so that displacements are continuous across the interfaces.

4. Bending and the extensional effects in the core are negligible.

5. Damping in the viscoelastic core is predominantly due to shear.

6. Rotary inertia effects in layers are negligible.

7. The force resultant in the middle viscoelastic layer is assumed to be negligible as its Young's modulus is very small compared to the module of the outer two layers. Kerwin's ${ }^{13}$ assumption is used, according to which $E_{f} A_{f}(x) U_{1, x}+E_{f} A_{f}(x) U_{3, x}=0$.

The expressions for potential energy, kinetic energy, and 


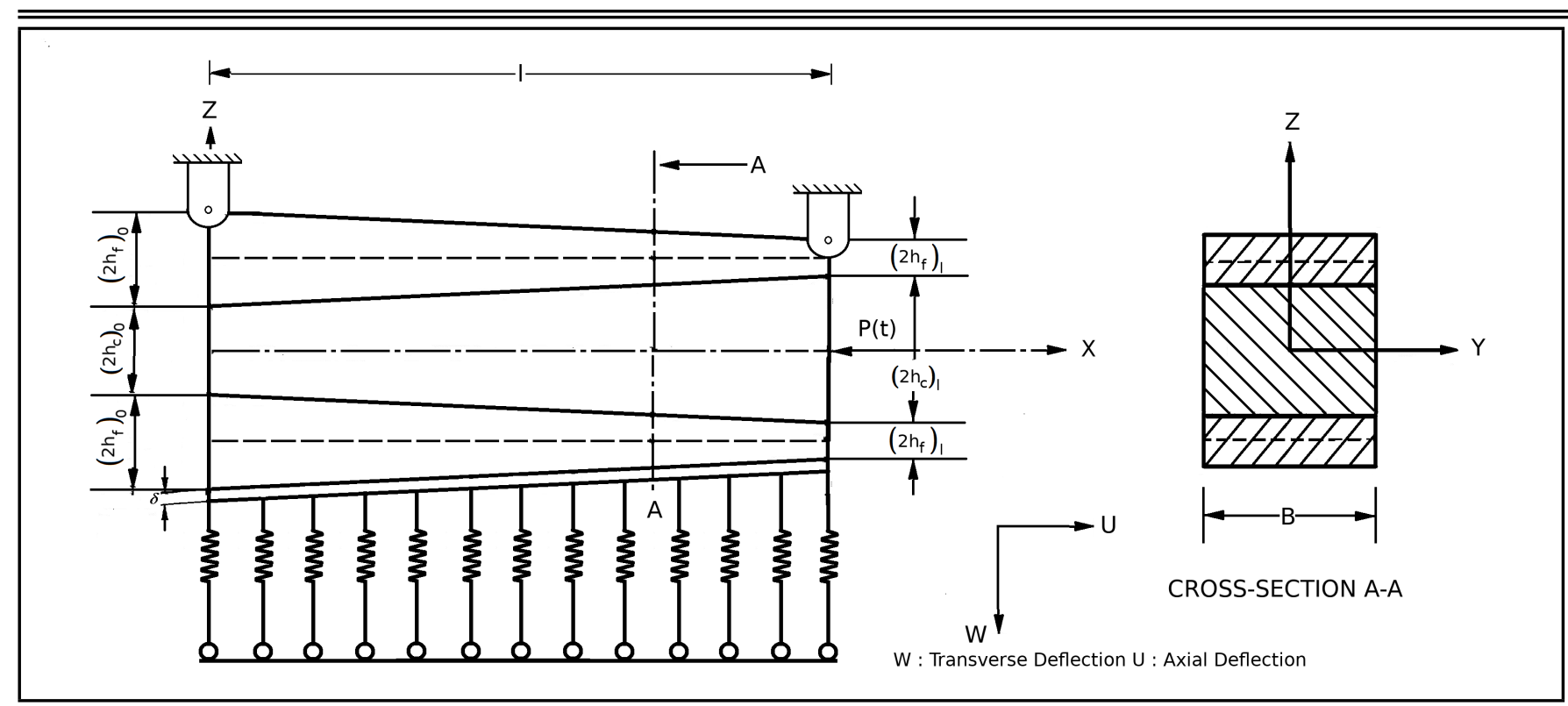

Figure 1. System configuration.

work done are as follows.

$$
\begin{gathered}
V=\frac{1}{2} \int_{0}^{l} E_{f} A_{f} U_{1, x}^{2} d x+\frac{1}{2} \int_{0}^{l} E_{f} A_{f} U_{3, x}^{2} d x+ \\
+\int_{0}^{l}\left(E_{f} I_{f}\right) w_{\prime x x}^{2} d x+\frac{1}{2} G_{2}^{*} \int_{0}^{l} A_{c} \gamma_{2}^{2} d x+ \\
+\frac{1}{2} G_{S} B \delta \int_{0}^{l} w_{\prime x}^{2} d x+\frac{B}{2} \int_{0}^{l} k(x) w^{2} d x ; \\
T=\frac{1}{2} \int_{0}^{l} m w_{\prime t}^{2} d x ; \\
w_{p}=\frac{1}{2} \int_{0}^{l} p(t) w_{\prime x}^{2} d x ;
\end{gathered}
$$

where $U_{1}$ and $U_{3}$ are the axial displacements in the top and bottom layers, $w_{\prime} x=\frac{\partial w}{\partial x}, w_{\prime} t=\frac{\partial w}{\partial t}$, and $\gamma_{2}$ is the shear strain in the middle layer given by $\gamma_{2}=\frac{U_{1}-U_{3}}{2 h_{c}}-\frac{C w_{x}}{2 h_{c}}$. The displacement $U_{3}$ is eliminated by using Kerwin's assumption. ${ }^{13}$

The application of Hamilton's principle, $\delta \int_{t_{1}}^{t_{2}}\left(T-V+w_{p}\right) d t=0$, leads to the following nondimensional equations of motion for the coupled axial and transverse displacement described by $U(x, t)$ and $w(x, t)$.

$$
\begin{array}{r}
{[2(1-\alpha \bar{x})+\mu(\beta+\alpha \bar{x})] \bar{w}^{\prime} \overline{t t}+\left[(1-\alpha \bar{x})^{3}+\right.} \\
\left.\frac{3}{2}(1-\alpha \bar{x})(2+2 \beta)^{2}\right] \bar{w}^{\prime} \overline{x x x x}+\left[\frac{3}{4} \lambda_{S}\left(\frac{l}{h_{f_{0}}}\right)^{3}\right] \bar{w}- \\
{\left[\frac{3}{4}\left(\frac{G_{S}}{E_{f}}\right)\left(\frac{\delta}{h_{f_{0}}}\right)\left(\frac{l}{h_{f_{0}}}\right)^{2}\right] \bar{w}^{\prime} \overline{x x}+} \\
\frac{3}{2}(2+2 \beta)^{2}(1-\alpha \bar{x})(\beta+\alpha \bar{x}) \bar{U}^{\prime} \overline{x x x}+\frac{P(t) l^{2}}{D_{f_{0}}} \bar{w}^{\prime} \overline{x x}=0 ;
\end{array}
$$

$$
(\beta+\alpha \bar{x}) \bar{U}_{\overline{x x}}+\bar{w}^{\prime} \overline{x x x}-\frac{1}{2}\left(\frac{G_{2}^{*}}{E_{f}}\right)\left(\frac{l}{h_{f_{0}}}\right)^{2} \bar{U}=0 ;
$$

where $\bar{w}^{\prime} \overline{x x}=\frac{\bar{w}}{l}, \bar{w}^{\prime} \overline{x x x x}=\frac{\partial^{4} \bar{w}}{\partial \bar{x}^{4}}, \bar{w}^{\prime} \overline{x x x}=\frac{\partial^{3} \bar{w}}{\partial \bar{x}^{3}}, \bar{w}^{\prime} \overline{x x}=\frac{\partial^{2} \bar{w}}{\partial \bar{x}^{2}}$, $\bar{U}=\frac{U}{l}, \bar{U}^{\prime} \overline{x x x}=\frac{\partial^{3} \bar{U}}{\partial \bar{x}^{3}}, \bar{U}_{\bar{\prime} \overline{x x}}=\frac{\partial^{2} \bar{U}}{\partial \bar{x}^{2}}, \mu=\frac{\rho_{c}}{\rho_{f}}, \alpha=\frac{h_{f_{0}}-h_{f_{l}}}{h_{f_{0}}}$, $\beta=\frac{h_{c_{0}}}{h_{f_{0}}}, \bar{x}=\frac{x}{l}, \lambda_{s}=\frac{k_{s} l}{E_{f}}$, and $D_{f_{0}}=2 E_{f} I_{f_{0}}$. The following are the associated boundary conditions to be satisfied at $\bar{x}=0$ and $\bar{x}=l$.

$$
\left(\frac{G_{s}}{E_{f}}\right)\left(\frac{\delta}{h_{f_{0}}}\right)\left(\frac{l}{h_{f_{0}}}\right) \bar{w}^{\prime} \bar{x}+\left(\frac{\bar{P}(\bar{t})}{E_{f} B h_{f_{0}}}\right) \frac{l}{h_{f_{0}}} \bar{w}_{\bar{x}}=0 ;
$$

or,

$$
\bar{w}=0
$$

$$
\frac{1}{3} \frac{(1-\alpha \bar{x})^{3}}{(1+\beta)^{2}} \bar{w}_{\prime} \overline{x x}+(\beta+\alpha \bar{x}) \bar{U}_{\prime \bar{x}}+\bar{w}_{\overline{x x}}=0 ;
$$

or,

$$
\begin{gathered}
\bar{w}^{\prime} \bar{x}=0 ; \\
(\beta+\alpha \bar{x}) \bar{U}^{\prime} \bar{x}+\bar{w}^{\prime} \overline{x x}=0 ;
\end{gathered}
$$

or,

$$
\bar{U}=0
$$

In the above, $\bar{t}=t / t_{0}, t_{0}=\left[\frac{\rho_{f} A_{f_{0}} l^{4}}{E_{f} I_{f_{0}}}\right]^{1 / 2}, \bar{P}_{0}=\frac{P_{0} l^{2}}{D_{f_{0}}}, \bar{P}_{1}=$ $\frac{P_{1} l^{2}}{D_{f_{0}}}$, and $\bar{P}=\bar{P}_{0}+\bar{P}_{1} \cos \bar{w} \bar{t}$. The various section dependent parameters are

$$
\begin{gathered}
g^{*}=\frac{1}{2}\left(\frac{G_{2}^{*}}{E_{f}}\right)\left(\frac{l}{h_{f_{0}}}\right)^{2} ; \\
Y=\frac{E_{f} A_{f_{0}} C^{2}}{2 D_{f_{0}}}=3(1+\beta)^{2} ; \\
C=2 h_{f_{0}}+2 h_{c_{0}} ;
\end{gathered}
$$

$$
\bar{m}=2(1-\alpha \bar{x})+\mu(\beta+\alpha \bar{x}) .
$$




\subsection{Approximate Solution}

Solutions of Eq. (4) and Eq. (5) are assumed in the form

$$
\begin{gathered}
\bar{w}(\bar{x}, \bar{t})=\sum_{i=l}^{i=p} w_{i}(\bar{x}) f_{i}(\bar{t}) \\
\bar{U}(\bar{x}, \bar{t})=\sum_{k=p+1}^{k=2 p} U_{k}(\bar{x}) f_{k}(\bar{t}) .
\end{gathered}
$$

Here, $w_{i}$ and $U_{k}$ are the shape functions and $f_{i}$ and $f_{k}$ are the generalized coordinates. The shape functions $w_{i}$ and $U_{k}$ are to be chosen to satisfy as many boundary conditions as possible. ${ }^{30}$ The shape functions used for the different boundary conditions are same as that of Ray and Kar. ${ }^{10}$

1. For the pinned-pinned (P-P) case, $w_{i}(\bar{x})=\sin (i \pi \bar{x})$, $U_{k}(\bar{x})=\cos (k \pi \bar{x})$.

2. For the clamped-clamped (C-C) case, $w_{i}(\bar{x})=\bar{x}^{(i+1)}-$ $2 \bar{x}^{(i+2)}+\bar{x}^{(i+3)}, U_{k}(\bar{x})=\bar{x}^{k}-\bar{x}^{(k+1)}$.

Substituting Eq. (13) and Eq. (14) in the energy expression of $V, T$ and $w_{p}$, then applying Galerkin method $\frac{d}{d t}\left[T+V-w_{p}\right]=0$ yields the following matrix equations of motion in the generalized coordinates.

$$
\begin{gathered}
{[m]\left\{\ddot{Q}_{1}\right\}+\left[K_{11}\right]\left\{Q_{1}\right\}-\left[K_{12}\right]\left\{Q_{2}\right\}=\{0\} ;} \\
{\left[K_{21}\right]\left\{Q_{1}\right\}+\left[K_{22}\right]\left\{Q_{2}\right\}=\{0\} ;}
\end{gathered}
$$

or,

$$
\left\{Q_{2}\right\}=-\left[K_{22}\right]^{-1}\left[K_{21}\right]\left\{Q_{1}\right\}=-\left[K_{22}\right]^{-1}\left[K_{12}\right]^{T}\left\{Q_{1}\right\} .
$$

Then, Eq. (15) can be written as

$$
[m]\left\{\ddot{Q}_{1}\right\}+\left[K_{11}\right]\left\{Q_{1}\right\}-\left[K_{12}\right]\left[K_{22}\right]^{-1}\left[K_{12}\right]^{T}\left\{Q_{1}\right\}=\{0\} ;
$$

or,

$$
[m]\left\{\ddot{Q}_{1}\right\}+\left(\left[K_{11}\right]-\left[K_{12}\right]\left[K_{22}\right]^{-1}\left[K_{12}\right]^{T}\right)\left\{Q_{1}\right\}=\{0\}
$$

where,

$$
\begin{gathered}
\left\{Q_{1}\right\}=\left\{f_{1}, \ldots, f_{p}\right\}^{T} ; \\
\left\{Q_{2}\right\}=\left\{f_{p+1}, \ldots, f_{2 p}\right\}^{T} ;
\end{gathered}
$$

also,

$$
\begin{gathered}
M_{i j}=\int_{0}^{1} \bar{m} w_{i} w_{j} d \bar{x} \\
K_{11 i j}=\left(2(1-\alpha \bar{x})^{3}+Y(1-\alpha \bar{x})\right) \int_{0}^{1} w^{\prime \prime}{ }_{i} w_{j} d \bar{x}+ \\
\left(\frac{G_{s}}{E_{f}}\right)\left(\frac{\delta}{l}\right)\left(\frac{l}{h_{f_{0}}}\right) \int_{0}^{1} w_{i}^{\prime} w_{j}^{\prime} d \bar{x}-\bar{P}\left(\frac{l}{h_{f_{0}}}\right)^{3} \int_{0}^{1} w_{i} w_{j} d \bar{x}+
\end{gathered}
$$

$$
\begin{gathered}
K_{12 j k}=K_{21 l i}=2 Y(1-\alpha \bar{x}) \int_{0}^{1} w^{\prime \prime} U_{k}^{\prime} d \bar{x} ; \\
K_{22 k l}=2 Y(1-\alpha \bar{x})(\beta+\alpha \bar{x})^{2} \int_{0}^{1} U_{k}^{\prime} U_{l}^{\prime} d \bar{x}+ \\
2 g^{*} Y \int_{0}^{1} U_{k} U_{l} d \bar{x} ; \\
{\left[K_{21}\right]=\left[K_{12}\right]^{T} .}
\end{gathered}
$$

The Eq. (15) and Eq. (16) are further simplified to

$$
\begin{array}{r}
{[m]\left\{\ddot{Q}_{1}\right\}+\left[[k]-\bar{P}_{0}[H]\right]\left\{Q_{1}\right\}-} \\
\bar{P}_{1} \cos (\bar{\omega} \bar{t})[H]\left\{Q_{1}\right\}=\{0\}
\end{array}
$$

where

$$
\begin{gathered}
{[k]=[\bar{k}]-\left[K_{12}\right]\left[K_{22}\right]^{-1}\left[K_{12}\right]^{T}} \\
H_{i j}=\int_{0}^{1} w_{i}^{\prime} w_{j}^{\prime} d \bar{x}
\end{gathered}
$$

and

$$
\begin{array}{r}
\bar{k}_{i j}=\left(2(1-\alpha \bar{x})^{3}+Y(1-\alpha \bar{x})\right) \int_{0}^{1} w^{\prime \prime}{ }_{i} w^{\prime \prime}{ }_{j} d \bar{x}+ \\
2 \lambda_{s}\left(\frac{l}{h_{f_{0}}}\right)^{3} \int_{0}^{1} w_{i} w_{j} d \bar{x}+ \\
\left(\frac{G_{s}}{E_{f}}\right)\left(\frac{\delta}{l}\right)\left(\frac{l}{h_{f_{0}}}\right) \int_{0}^{1} w_{i}^{\prime} w_{j}^{\prime} d \bar{x}-\bar{P}_{0} \int_{0}^{1} w_{i}^{\prime} w_{j}^{\prime} d \bar{x} .
\end{array}
$$

\subsection{Static Buckling Loads}

The substitution of $\bar{P}_{1}=0$ and $\left\{\ddot{Q}_{1}\right\}=0$ in Eq. (27) leads to the eigenvalue problem $[k]^{-1}[H]\left\{Q_{1}\right\}=\frac{1}{P_{0}}\left\{Q_{1}\right\}$. The static buckling loads $\left(P_{0}\right)_{\text {crit }}$ for the first few modes are obtained as the real parts of the reciprocals of the eigenvalues of $[k]^{-1}[H]$.

\subsection{Regions of Instability}

Equation (27) can be re-written in the form

$$
\ddot{Q}_{1}+[L]\left\{Q_{1}\right\}+2 \varepsilon \cos (\bar{\omega} \bar{t})[B]\left\{Q_{1}\right\}=\{0\}
$$

where $[L]=[M]^{-1}\left[[k]-\bar{P}_{0}[H]\right], \quad[B]=$ $-[L]^{-1}[M]^{-1}[H][L]$ and $\varepsilon=\frac{\bar{P}_{1}}{2}$. The linear transformation $\left\{Q_{1}\right\}=[Z]\{U\}$ is introduced in Eq. (31), where $[Z]$ is a nonsingular matrix such that $[Z]^{-1}[L][Z]$ is a Jordan canonical form. Multiplying the result by $[Z]^{-1}$ yields

$$
\begin{array}{r}
\ddot{U}_{N}+\omega_{N}^{* 2} U_{N}+2 \varepsilon \cos \bar{\omega} \bar{t} \sum_{M=1}^{M=p} b_{N M} U_{M}=0 \\
N=1,2, \ldots P
\end{array}
$$

where $b_{N M}=b_{N M, R}+j b_{N M, I}$ are complex constant and elements of $[B], \omega_{N}^{*}=\omega_{N, R}+j \omega_{N, I}$ is the $N^{\text {th }}$ natural frequency 
of the system. $\omega_{N}^{*}$ are the distinct eigenvalues of the system, and $\{U\}$ is a new set of generalized co-ordinates.

The boundaries of the region of instability of the main and of the combination resonances are obtained using the following conditions by Saito and Otomi. ${ }^{14}$

\subsubsection{Case (A) Main Resonance}

In this case, the regions of instability are given by

$$
\left|\frac{\bar{\omega}}{2}-\bar{\omega}_{\mu, R}\right|<\frac{1}{4} \sqrt{\left(\frac{\bar{P}_{1}^{2}\left(b_{\mu \mu, R}^{2}+b_{\mu \mu, I}^{2}\right)}{\bar{\omega}_{\mu, R}^{2}}-16 \bar{\omega}_{\mu, I}^{2}\right)} .
$$

for the damped case and

$$
\left|\frac{\bar{\omega}}{2}-\bar{\omega}_{\mu, R}\right|<\frac{1}{4}\left|\frac{\bar{P}_{1} b_{\mu \mu, R}}{\bar{\omega}_{\mu, R}}\right| ;
$$

for the un-damped case, $\mu=1,2, \ldots, N$.

\subsubsection{Case (B) Combination Resonance of Sum Type}

This type of resonance occurs when $\mu \neq v, \mu>v \mu, v=$ $1,2, \ldots, N$ and the regions of instability are given by

$$
\begin{gathered}
\left|\frac{\bar{\omega}}{2}-\frac{1}{2}\left(\bar{\omega}_{\mu, R}+\bar{\omega}_{v, R}\right)\right|<\frac{\bar{\omega}_{\mu, I}+\bar{\omega}_{v, I}}{8 \sqrt{\bar{\omega}_{\mu, I} \bar{\omega}_{v, I}}} \\
\left(\sqrt{\frac{\bar{P}_{1}^{2}}{\bar{\omega}_{\mu, R} \bar{\omega}_{v, I}}\left(b_{\mu v, R} b_{v \mu, R}+b_{v \mu, I} b_{\mu v, I}\right)-16 \bar{\omega}_{\mu, I} \bar{\omega}_{v, I}}\right)
\end{gathered}
$$

for the damped case and,

$$
\left|\frac{\bar{\omega}}{2}-\frac{1}{2}\left(\bar{\omega}_{\mu, R}+\bar{\omega}_{v, R}\right)\right|<\frac{\bar{P}_{1}}{4} \sqrt{\frac{b_{\mu v, R} b_{v \mu, R}}{\bar{\omega}_{\mu, R} \bar{\omega}_{v, R}}}
$$

for the un-damped case.

\subsubsection{Case (C) combination resonance of difference type}

This type of resonance occurs when $\mu<v,(\mu, v=$ $1,2, \ldots, N)$ and the regions of instability are given by

$$
\begin{array}{r}
\left|\frac{\bar{\omega}}{2}-\frac{1}{2}\left(\bar{\omega}_{v, R}-\bar{\omega}_{\mu, R}\right)\right|< \\
\frac{\bar{\omega}_{\mu, I}+\bar{\omega}_{v, I}}{8 \sqrt{\bar{\omega}_{\mu, I}+\bar{\omega}_{v, I}}} \\
\sqrt{\frac{\bar{P}_{1}^{2}}{\bar{\omega}_{\mu, R} \bar{\omega}_{v, R}}\left(-b_{\mu v, R} b_{v \mu, R}+b_{\mu v, I} b_{v \mu}-16 \bar{\omega}_{\mu, I} \bar{\omega}_{v, I}\right)}
\end{array}
$$

for the damped case and

$$
\left|\frac{\bar{\omega}}{2}-\frac{1}{2}\left(\bar{\omega}_{v, R}-\bar{\omega}_{\mu, R}\right)\right|<\frac{\bar{P}_{1}}{4} \sqrt{\frac{-b_{\mu v, R} b_{v \mu, R}}{\bar{\omega}_{\mu, R} \bar{\omega}_{\mu, R}}} ;
$$

for the un-damped case.
Table 1. Comparison of static buckling load.

\begin{tabular}{||c|c|c|c||}
\hline $\begin{array}{c}\text { End arrangement of the } \\
\text { sandwich beam }\end{array}$ & Mode & $\begin{array}{c}\text { Present } \\
\text { analysis }\end{array}$ & $\begin{array}{c}\text { Kar and Sujata } \\
\text { from figures } \\
2 \text { and } 3\end{array}$ \\
\cline { 2 - 4 } & 1 & 20.3 & 20.2 \\
(For shear parameter with & 1 & 60.15 & 60 \\
$Y=50, \alpha=0, g=0.1)$ & 2 & 110.2 & 110 \\
\hline Clamped-free & 3 & 20.7 & 20.5 \\
(For taper parameter with & 1 & 60.15 & 60 \\
$Y=50, g=0.1, \alpha=0.2)$ & 2 & 108.6 & 108.5 \\
Clamped-free & 3 & \multicolumn{2}{|r}{} \\
\hline
\end{tabular}

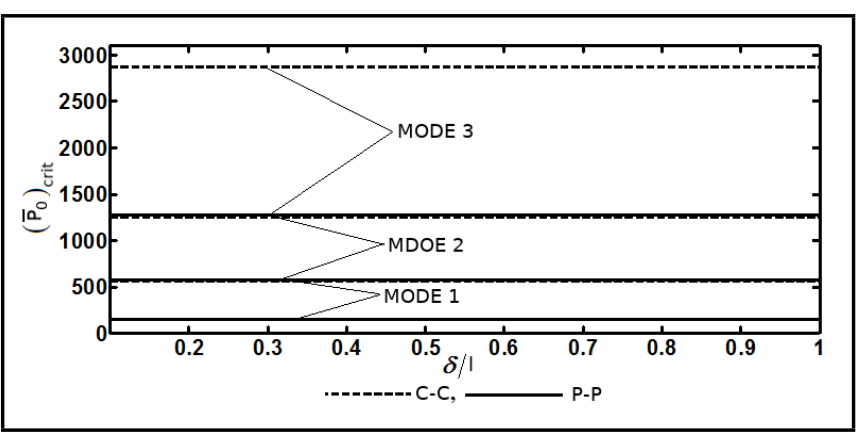

Figure 2. Variation of $\left(\bar{P}_{0}\right)_{\text {crit }}$ with $\delta / l$.

\section{NUMERICAL RESULTS AND DISCUSSION}

The symmetric sandwich beam is assumed to rest on a variable Pasternak foundation with stiffness of the elastic foundation is assumed to have a parabolic variation of the form, $k(\bar{x})=\left\{1+4\left(1-\gamma_{e}\right)\left(\bar{x}^{2}-\bar{x}\right)\right\}$, where $\gamma_{e}$ is the elastic foundation parameter. ${ }^{31}$

\subsection{Validation of the results}

Taking the following nondimensional parameters of the sandwich beam as given in Kar and Sujata, ${ }^{9}$ the static buckling loads of the sandwich beam without a Pasternak foundation have been determined. The core loss factor $\eta_{c}=0.3$, core density parameter $\mu=0.05$, and shear parameter $g=0.1$ have been considered here. The static buckling loads for clampedfree end conditions have been determined for the first three modes as given in Table 1. It may be observed that these results are in good agreement with those obtained by Kar and Sujata. ${ }^{9}$

This was expected as the equation of motion reduces to that of Kar and Sujata9 in the absence of a Pasternak foundation. This validates the code developed in the present work using MATLAB.

As the static buckling loads obtained using the present analysis are in good agreement with Kar and Sujata, ${ }^{9}$ the static buckling loads and regions of instability of the sandwich beam resting on a variable Pasternak foundation under P-P and C-C end conditions is discussed in the following section.

\subsection{Static figures}

Figure 2 shows the effect of $\delta / l$ on the static buckling loads. The buckling loads of all the modes slightly increase with an increase in the value of $\delta / l$. The buckling loads for the $\mathrm{C}-\mathrm{C}$ case are greater than the P-P case for all the modes.

The static buckling loads for varying values of $G_{2} / E_{f}$ are shown in Fig. 3. This shows that the static buckling loads 
Table 2. Variation of $\left(\bar{P}_{0}\right)_{c r i t}$ with $G_{S} / E_{f}$.

\begin{tabular}{|c|c|c|c|c|c|c|c|c|c|c|c|}
\hline & $G_{S} / E_{f}$ & 0.1 & 0.2 & 0.3 & 0.4 & 0.5 & 0.6 & 0.7 & 0.8 & 0.9 & 1 \\
\hline \multirow{3}{*}{ U' } & MODE 1 & 565.967 & 566.067 & 566.167 & 566.267 & 566.367 & 566.467 & 566.567 & 566.667 & 566.767 & 566.867 \\
\hline & MODE 2 & 1249.3 & 1249.4 & 1249.5 & 1249.6 & 1249.7 & 1249.8 & 1249.9 & 1250 & 1250.1 & 1250.2 \\
\hline & MODE 3 & 2868.1 & 2868.2 & 2868.3 & 2868.4 & 2868.5 & 2868.6 & 2868.7 & 2868.8 & 2868.9 & 2869 \\
\hline \multirow{3}{*}{ a } & MODE 1 & 142.3908 & 142.4908 & 142.5908 & 142.6908 & 142.7908 & 142.8908 & 142.9908 & 143.0908 & 143.1908 & 143.2908 \\
\hline & MODE 2 & 565.1648 & 565.2648 & 565.3648 & 565.4648 & 565.5648 & 565.6648 & 565.7648 & 565.8648 & 565.9648 & 566.0648 \\
\hline & MODE 3 & 1270.8 & 1270.9 & 1271 & 1271.1 & 1271.2 & 1271.3 & 1271.4 & 1271.5 & 1271.6 & 1271.7 \\
\hline
\end{tabular}

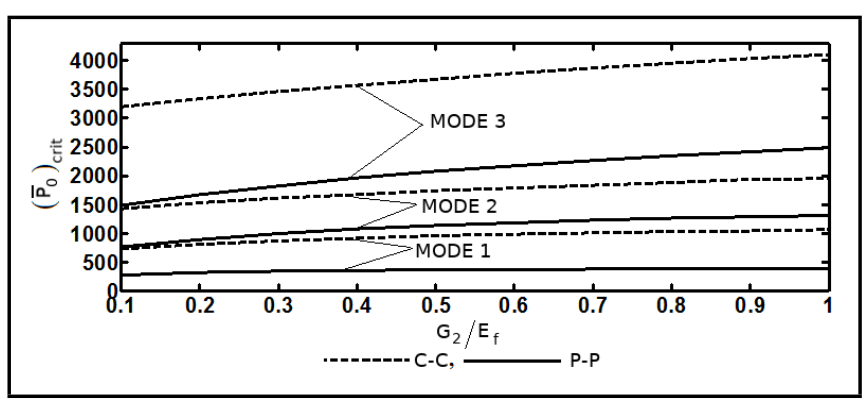

Figure 3. Variation of $\left(\bar{P}_{0}\right)_{\text {crit }}$ with $G_{2} / E_{f}$.

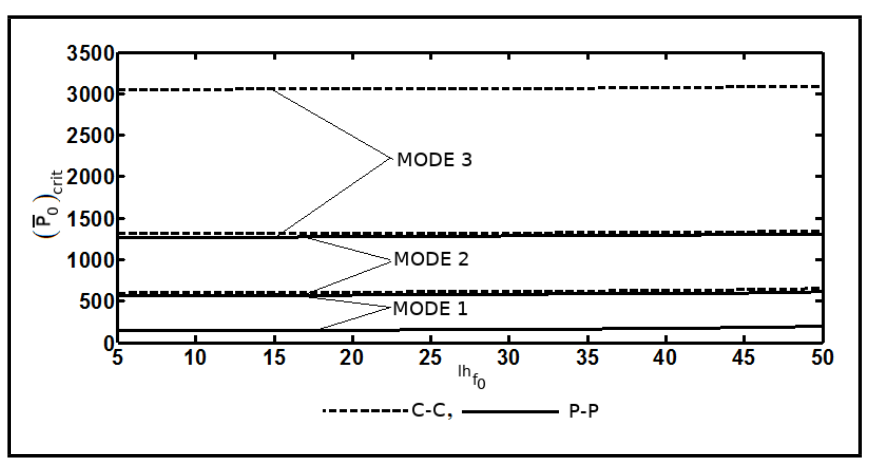

Figure 4. Variation of $\left(\bar{P}_{0}\right)_{\text {crit }}$ with $G_{2} / E_{f}$.

for all three modes increase with an increase in the value of $G_{2} / E_{f}$ for both the C-C and P-P cases. The static buckling loads increase with an increase in the value of $G_{2} / E_{f}$, as it improves the shearing characteristics of the viscoelastic layer which increases the rigidity of the system, hence indicating stabilization.

The static buckling loads marginally increase with an increase in the value of $G_{s} / E_{f}$. Because of variation, Table 2 is given instead of a graph. As $G_{s}$ improves the stiffness of the system, it increases the stability of the system.

Figure 4 address the effect of $l h_{f_{0}}$ on the static buckling loads. An increase in the value of $l h_{f_{0}}$ increases the buckling loads of all the modes for both the C-C and P-P boundary conditions. The $\mathrm{C}-\mathrm{C}$ case has more static buckling load than the $\mathrm{P}-\mathrm{P}$ case for all modes.

The static buckling loads are independent of $\mu$ and $\eta$ for all the modes for both end conditions, so the graphs are not presented here.

The effect of change in the value of $\gamma_{e}$ on the static buckling loads is shown in Fig. 5. An increase in the value of $\gamma_{e}$ increases the buckling loads of all the modes for both the C-C and P-P cases, which is obvious. Table 3 is provided for better clarity.

Figure 6 shows the variation of static buckling loads with a change in the value of $Y$. The static buckling loads increase linearly with an increase in the value of $Y$ for all the modes for
Table 3. Variation of $\left(\bar{P}_{0}\right)_{c r i t}$ with $\gamma_{e}$.

\begin{tabular}{|c|c|c|c|c|c|c|}
\hline & $\gamma_{e}$ & 0.01 & 0.1 & 1 & 10 & 20 \\
\hline \multirow{3}{*}{ U' } & MODE 1 & 607.15 & 607.32 & 609.08 & 626.58 & 645.99 \\
\hline & MODE 2 & 1316.9 & 1316.9 & 1317.4 & 1322.5 & 1328.1 \\
\hline & MODE 3 & 3061.9 & 3061.9 & 3062.6 & 3068.7 & 3075.5 \\
\hline \multirow{3}{*}{ a' } & MODE 1 & 147.36 & 147.71 & 151.21 & 186.23 & 225.14 \\
\hline & MODE 2 & 570.82 & 570.91 & 571.78 & 580.54 & 590.27 \\
\hline & MODE 3 & 1276.6 & 1276.7 & 1277 & 1280.9 & 1285.3 \\
\hline
\end{tabular}

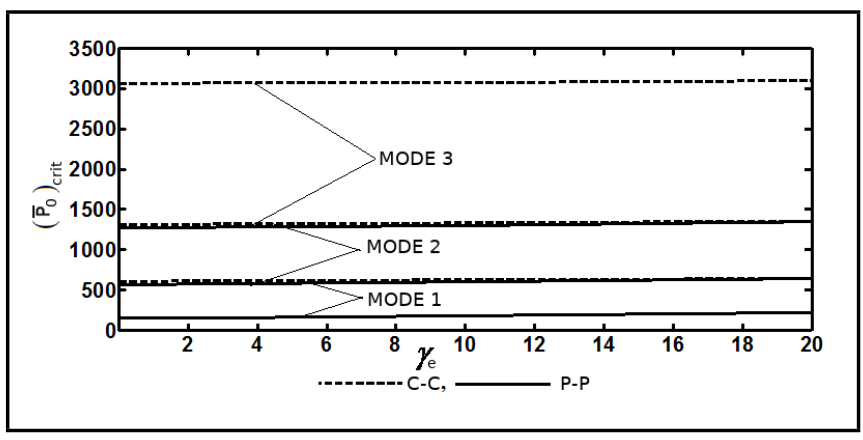

Figure 5. Variation of $\left(\bar{P}_{0}\right)_{c r i t}$ with $\gamma_{e}$.

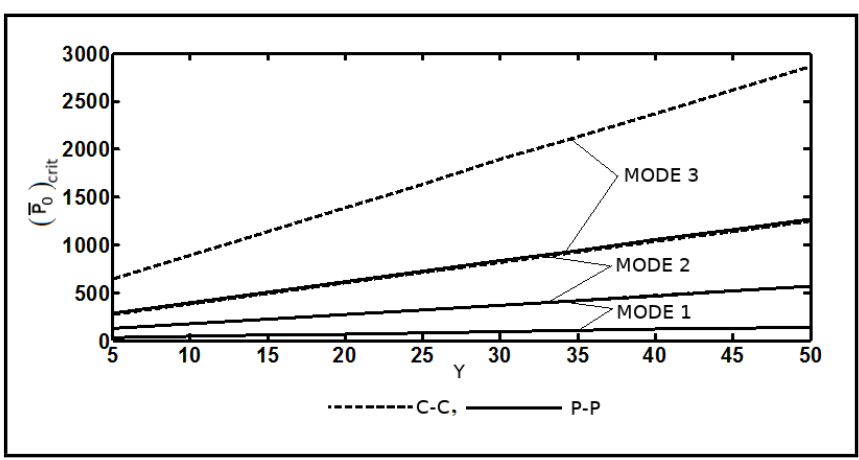

Figure 6. Variation of $\left(\bar{P}_{0}\right)_{\text {crit }}$ with $Y$.

both of the considered boundary conditions. With an increase in the value of $Y$, the rigidity of the system increases, so the static buckling load increases for all the considered cases. The static buckling load for C-C is greater than that of the P-P case.

The static buckling loads for varying $\alpha$ are plotted in Fig. 7, which shows that the static buckling loads of all the modes decrease with an increase in the value of $\alpha$. The variation is nonlinear in nature and the nonlinearity is greater in the third mode for the $\mathrm{C}-\mathrm{C}$ case.

Figure 8 shows the effects of $\beta$ on the static buckling loads. The static buckling load increases with an increase in the value of $\beta$ in all three modes for both the C-C and P-P cases. The $\mathrm{C}-\mathrm{C}$ has greater static buckling loads than the P-P case.

From Figs. 2 through 8 , it is clear that the C-C case is stati- 


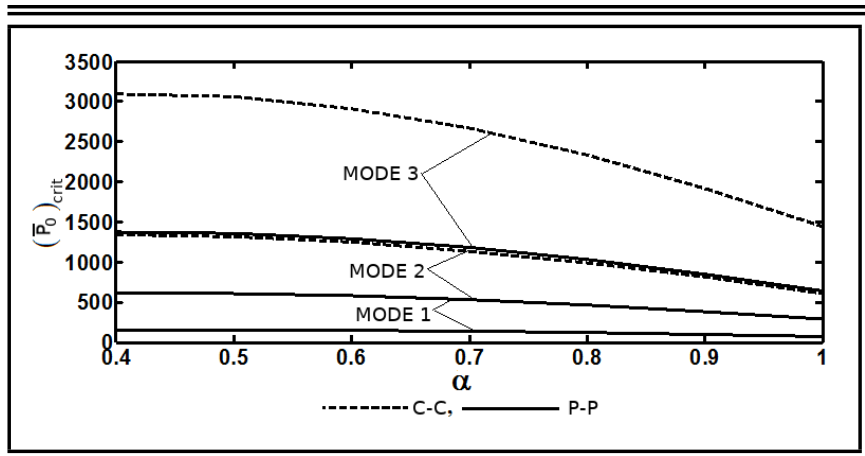

Figure 7. Variation of $\left(\bar{P}_{0}\right)_{\text {crit }}$ with $\alpha$.

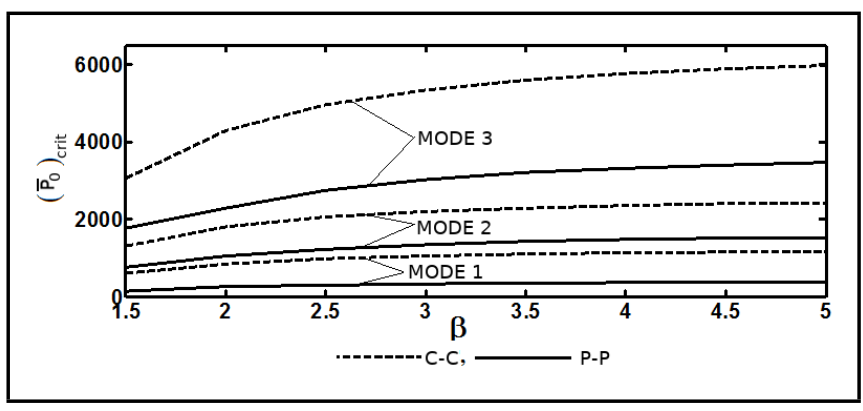

Figure 8. Variation of $\left(\bar{P}_{0}\right)_{c r i t}$ with $\beta$.

cally more stable than the P-P case. This is because of greater rigidity in the $\mathrm{C}-\mathrm{C}$ case in comparison to the $\mathrm{P}-\mathrm{P}$ case.

\subsection{Dynamic figures}

\subsubsection{Pinned-Pinned (P-P) case}

Figures 9 through 16 display the instability regions with the change in the value of different parameters for the P-P case.

As shown in Fig. 9, with an increase in the value of $\alpha$, the instability zones shift towards lower frequency regions, hence the destabilization of the system.

The effect of change in the value of $\beta$ on the instability zones is depicted in Fig. 10. An increase in the value of $\beta$ from 1.5 to 2.5 has not only shifted the zones towards higher frequency regions but has also reduced their areas by improving the stability of the system.

The effect of $\delta / l$ on the zones of instability of the system is marginal. The zones are shifted towards higher excitation frequencies with an increase in $\delta / l$. Due to very small variations, it is difficult to distinguish the variation from a graph. For better clarity, Table 4 contains the data obtained from MATLAB programming.

The stability diagram for the varying values of $G_{2} / E_{f}$ is shown in Fig. 11. Due to an increase in the value of $G_{2} / E_{f}$ from 0.0005 to 0.002 , the instability regions move upwards and shift towards higher frequency regions, thus indicating stabilization of the system.

The effect of $G_{s} / E_{f}$ on the instability regions of the system and the values obtained are given in Table 5, showing a stabilizing effect.

The effect of $l h_{f_{0}}$ upon the instability zones of the system is considered in Fig. 12. With an increase in the value of $l h_{f_{0}}$, the system stability improves as the instability zones move upwards and shift towards the right.

Figure 13 shows the influence of $\mu$ on the parametric instability. An increase in the value of $\mu$ relocates the resonance zones to lower excitation frequencies, hence indicating destabilization. The stabilizing effect of $\mu$ is clear from Table 6 .

Figures 14 and 15 depict the effect of change in the value of $\gamma_{e}$. The case $\gamma_{e}<1$ can be interpreted as a weakening of the elastic foundation and that of $\gamma_{e}>1$ as strengthening of the foundation as compared to a foundation with a constant modulus $\left(\gamma_{e}=1\right)$, for $\gamma_{e}>1$ improves the stability of the system as the instability zones shift towards higher excitation frequencies as shown in Fig. 15. As shown in Fig. 14, has a destabilizing effect on the system.

Figure 16 reveals that an increase in the value of shifts the instability zones towards higher excitation frequencies and reduces their areas with a constant vertical position, hence improving the stability of the system.

\subsubsection{Clamped-clamped (C-C) case}

The stability diagrams for $\beta=1.5$ and 2.5 with $g=$, $\mu=0.05, Y=50$ are shown in Figs. 17 and 18. An increase in the value of from 1.5 to 2.5 narrows all the zones and shifts them towards higher excitation frequencies, thus indicating stabilization. A combination resonance of $\left(\omega_{1}+\omega_{3}\right)$ and $\left(\omega_{2}+\omega_{4}\right)$ appears in both the cases.

The instability regions for $\delta / l=0.5$ and 0.1 with $g=0.1$, $\mu=0.05, Y=50$ are shown in Figs. 19 and 20. With an increase in the value of $\delta / l$ from 0.1 to 0.5 , all the instability regions are shifted slightly towards a higher frequency and for both the cases, a combination resonance of $\left(\omega_{1}+\omega_{3}\right)$ and $\left(\omega_{2}+\right.$ $\left.\omega_{4}\right)$ appears. Although the variation is marginal, it still has a stabilizing effect.

Figures 21 and 22 depict the effect of an increase in the value of $G_{2} / E_{f}$ from 0.001 to 0.005 for $g=0.1, \mu=0.05, Y=50$. The stability regions in Fig. 22 are shifted towards the right and moved upwards in comparison to Fig. 21. The combination resonance $\left(\omega_{1}+\omega_{3}\right)$ and $\left(\omega_{2}+\omega_{4}\right)$ also shifted towards higher excitation frequencies, hence indicating stabilization.

The stability diagrams for two different values of $G_{s} / E_{f}$ with $g=0.1, \mu=0.05, Y=50$ are shown in Figs. 23 and 24 . There is a marginal change in the stability of the system due to a very small movement of the instability regions towards the right by increasing the value of $G_{s} / E_{f}$ from 0.0005 to 0.002 .

Figures 25 and 26 show the regions of parametric resonance with $g=0.1, \mu=0.05$, and $h_{1}=35$ and 50 respectively. The increase in the value of $l h_{f_{0}}$ from 35 to 50 is observed to have shifted the instability zones towards higher excitation frequencies and upwards. Further, the width of most of the zones are decreased, thus it has a stabilizing effect.

The instability regions with $g=0.1, \mu=0.05$, and $Y=15$ and 30 are shown in Figs. 27 and 28, respectively. It is observed that with an increase in the value of $\gamma$, the resonance zones are shifted to higher forcing frequencies. Additionally, the combination resonance $\left(\omega_{2}+\omega_{3}\right)$ has disappeared due to the increase in the value of $Y$, thus indicating the stabilization of the system.

Figures 29 and 30 show the regions of parametric resonance with $g=0.1, Y=50$, and $\mu=0.5$ and 0.9 , respectively. The increase in the value of $\mu$ from 0.5 to 0.9 has shifted all the resonance zones along with the combination resonance zones to lower excitation frequencies, thus indicating destabilization. 
Table 4. Variation of $\left(\bar{P}_{0}\right)_{c r i t}$ with $\delta / l$.

\begin{tabular}{|c|c|c|c|c|c|c|c|c|c|c|}
\hline & \multirow{2}{*}{$\begin{array}{r}\text { Sl } \\
\text { No } \\
\end{array}$} & \multicolumn{3}{|c|}{$\delta / l=0.05$} & \multicolumn{3}{|c|}{$\delta / l=0.5$} & \multicolumn{3}{|c|}{$\delta / l=1$} \\
\hline & & $P_{1}$ & $\omega_{a}$ & $\omega_{b}$ & $P_{1}$ & $\omega_{a}$ & $\omega_{b}$ & $P_{1}$ & $\omega_{a}$ & $\omega_{b}$ \\
\hline \multirow{4}{*}{$\begin{array}{l}\overrightarrow{1} \\
\text { के } \\
\frac{0}{\Sigma}\end{array}$} & 1 & 0.14 & 58.909 & 58.903 & $\overline{0.14}$ & 58.9106 & 58.9043 & 0.14 & 58.9125 & 58.9063 \\
\hline & 2 & 0.78 & 58.982 & 58.829 & 0.78 & 58.9838 & 58.8311 & 0.78 & 58.9857 & 58.833 \\
\hline & 3 & 1.42 & 59.046 & 58.765 & 1.42 & 59.048 & 58.7669 & 1.42 & 59.0499 & 58.7689 \\
\hline & 4 & 1.74 & 59.078 & 58.733 & 1.74 & 59.0799 & 58.7349 & 1.74 & 59.0819 & 58.7369 \\
\hline \multirow{4}{*}{$\begin{array}{l}\text { N } \\
\text { 깅 } \\
\text { Oे } \\
\Sigma\end{array}$} & 1 & 0.16 & 231.34 & 231.32 & 0.16 & 231.338 & 231.323 & 0.16 & 231.34 & 231.325 \\
\hline & 2 & 0.8 & 231.41 & 231.25 & 0.8 & 231.411 & 231.251 & 0.8 & 231.412 & 231.253 \\
\hline & 3 & 1.44 & 231.47 & 231.18 & 1.44 & 231.476 & 231.186 & 1.44 & 231.478 & 231.188 \\
\hline & 4 & 1.76 & 231.51 & 231.15 & 1.76 & 231.509 & 231.153 & 1.76 & 231.51 & 231.155 \\
\hline \multirow{4}{*}{$\begin{array}{l}m \\
\text { wै } \\
\text { के } \\
\Sigma\end{array}$} & 1 & 0.16 & 518.86 & 518.85 & 0.16 & 518.863 & 518.848 & 0.16 & 518.865 & 518.85 \\
\hline & 2 & 0.8 & 518.93 & 518.77 & 0.8 & 518.935 & 518.775 & 0.8 & 518.937 & 518.777 \\
\hline & 3 & 1.44 & 519 & 518.71 & 1.44 & 519.001 & 518.71 & 1.44 & 519.003 & 518.712 \\
\hline & 4 & 1.76 & 519.03 & 518.68 & 1.76 & 519.034 & 518.677 & 1.76 & 519.035 & 518.679 \\
\hline \multirow{4}{*}{ 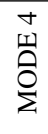 } & 1 & 0.16 & 921.41 & 921.4 & 0.16 & 921.417 & 921.403 & 0.16 & 921.419 & 921.405 \\
\hline & 2 & 0.8 & 921.49 & 921.33 & 0.8 & 921.49 & 921.33 & 0.8 & 921.492 & 921.332 \\
\hline & 3 & 1.44 & 921.55 & 921.26 & 1.44 & 921.556 & 921.264 & 1.44 & 921.558 & 921.266 \\
\hline & 4 & 1.76 & 921.59 & 921.23 & 1.76 & 921.588 & 921.231 & 1.76 & 921.59 & 921.234 \\
\hline
\end{tabular}

Table 5. Variation of $\left(\bar{P}_{0}\right)_{c r i t}$ with $G_{S} / E_{f}$.

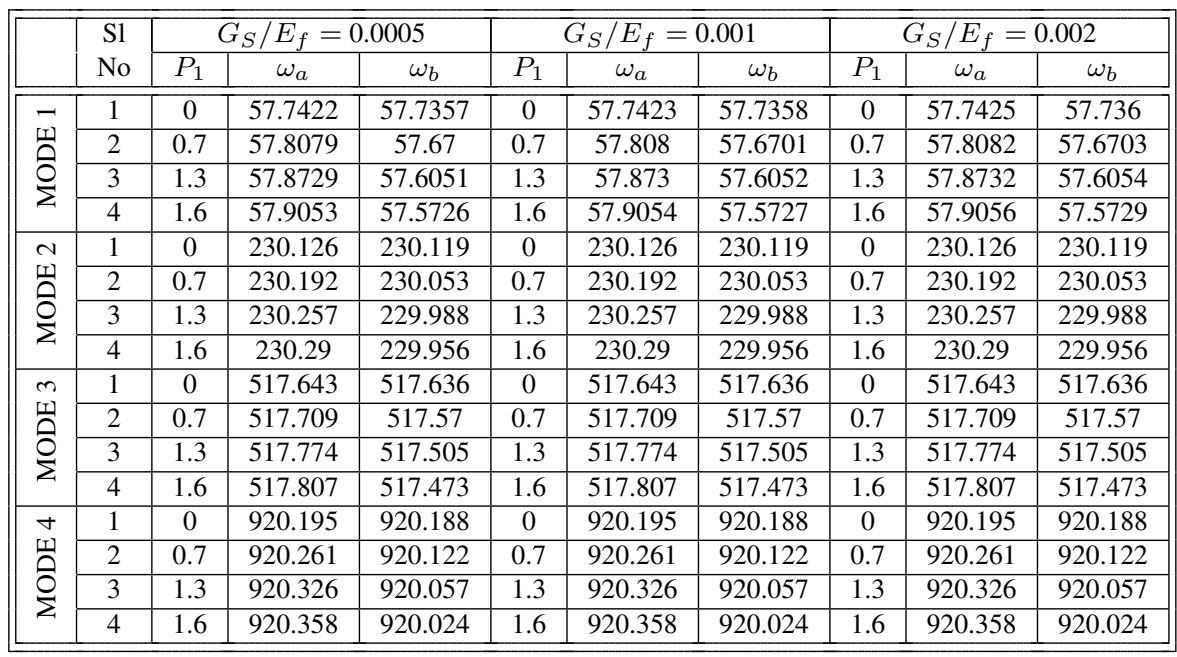

Table 6. Variation of $\left(\bar{P}_{0}\right)_{\text {crit }}$ with $\eta$.

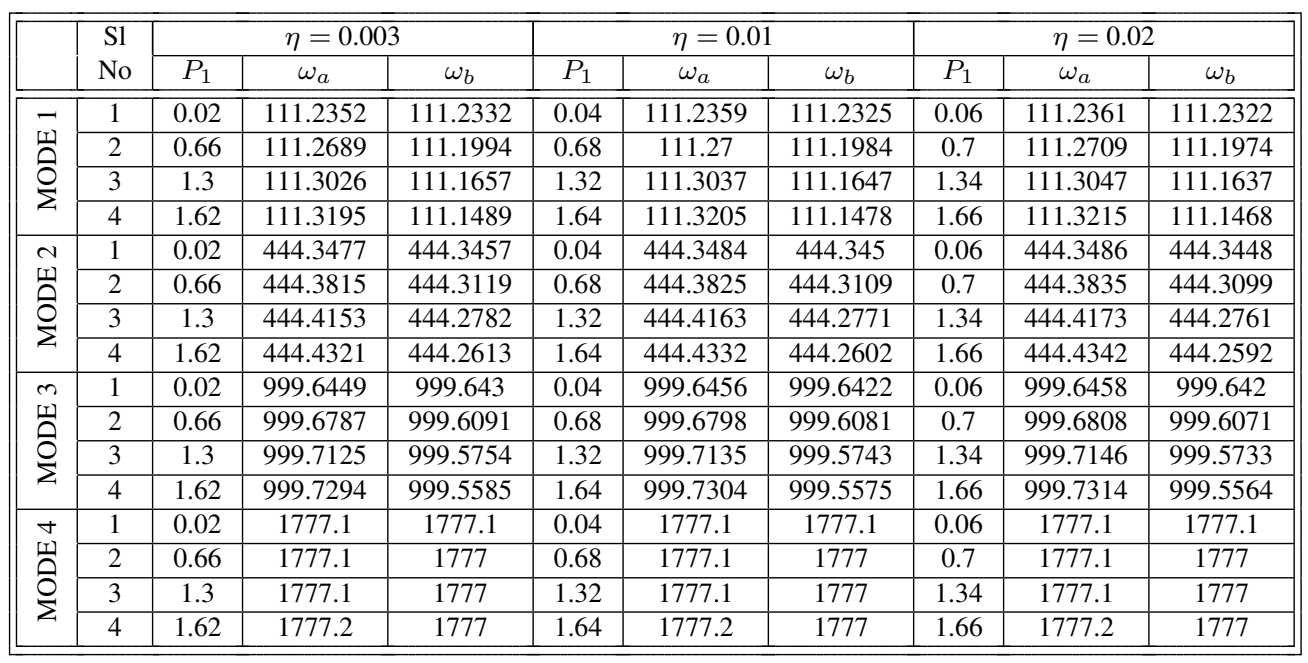




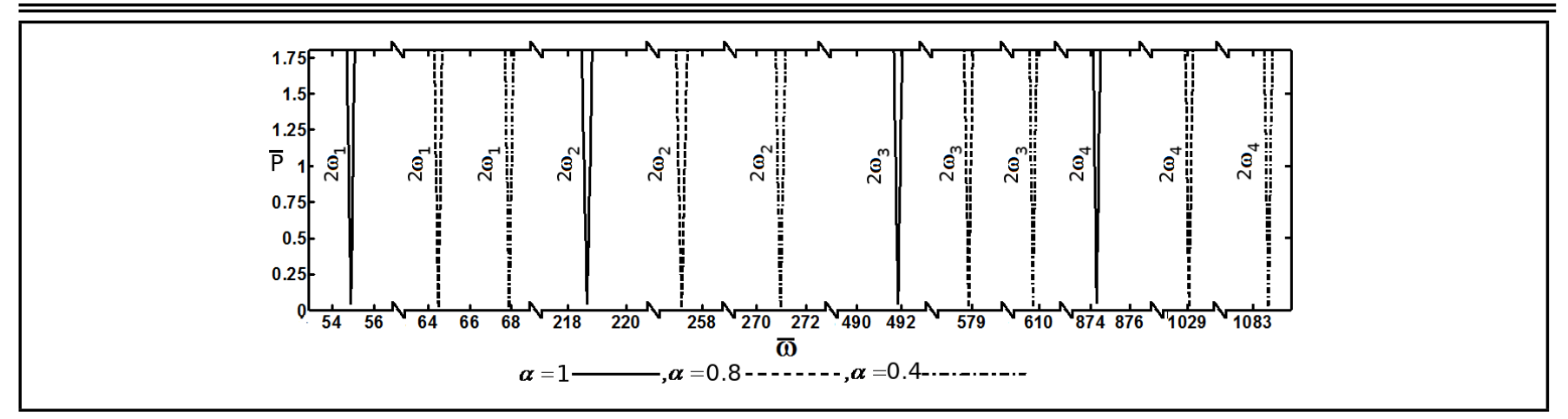

Figure 9. Effect of $\alpha$ on the instability zones.

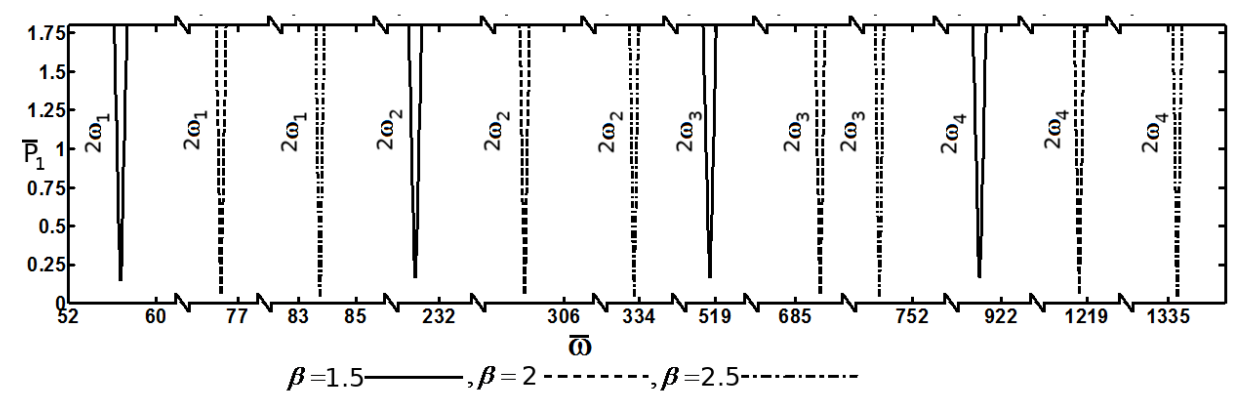

Figure 10. Effect of $\beta$ on the instability zones.

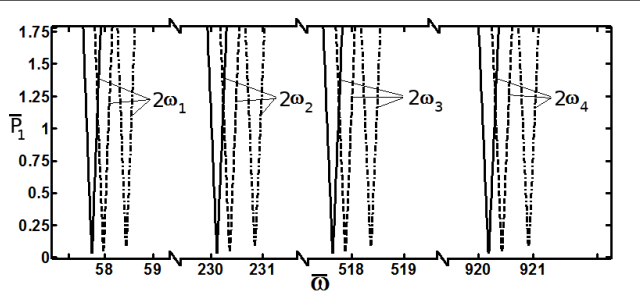

$\mathrm{G}_{2} / \mathrm{E}_{\mathrm{f}}=0.0005$

Figure 11. Effect of $G_{2} / E_{f}$ on the instability zones.

Figures 31 and 32 address the effect of an increase in the value of $\eta$ from 0.05 to 0.5 for $\mathrm{g}=0.1, \mu=0.05$, and $Y=50$. All the resonance zones have moved upwards, reducing the areas, hence improving the stability of the system.

As shown in Figs. 33 and 34, the effect of an increase in the value of from 0.2 to 2 for $g=0.1, Y=50$, and $\mu=0.05$ is an increase in the stability of the system by shifting the resonance zones to higher excitation frequencies and moving upwards.

Figures 35 and 36 address the effect of an increase in the value of $\alpha$ from 0.2 to 0.8 for $g=0.1, \mu=0.05$, and $Y=50$. All the resonance zones have shifted towards lower excitation frequencies, hence decreasing the stability of the system.

With an increase in the value of $\eta, \delta / l, G_{2} / E_{f}, G_{S} / E_{f}$, $l h_{f_{0}}, \gamma_{e}, Y$ and $\beta$, the value of $[k]$ increases, thus improving the stability of the system. With the increase in the values of $\mu$ and $\alpha$, the value of $[k]$ decreases, which worsens the stability of the system, hence the results addressing the effects of various parameters on the static buckling loads and regions of instability are justified.

\section{CONCLUSIONS}

The static and dynamic stability of a tapered symmetric sandwich beam with a viscoelastic core resting on a variable
Pasternak foundation under the action of a pulsating axial load is investigated for pinned-pinned and clamped-clamped end conditions by computational analysis. By using Saito-Otomi conditions, the zones of instability have been obtained. The results have been compared with results of earlier researchers ${ }^{9}$ to test the validity of the analysis.

The results reveal that the static buckling loads are almost independent of $\eta$ and $\mu$. An increase in the value of $\alpha$ reduces the static buckling load for both the P-P and C-C cases. Higher values of $G_{2} / E_{f}, G_{S} / E_{f}, l h_{f_{0}}, Y, \delta / l, \gamma_{e}$, and $\beta$ improve the static buckling loads for both the cases considered in the analysis. The static buckling loads for the $\mathrm{C}$-C case are greater than the P-P case for all the parameters considered in this analysis.

From the analysis it is found that the dynamic stability of the system increases with an increase in the values of $G_{2} / E_{f}$, $G_{S} / E_{f}, Y, l h_{f_{0}}, \delta / l, \beta$, and $\eta$, with increments of $\mu$ and $\alpha$ worsening the stability of the system. Weakening of the foundation makes the system more susceptible to periodic forces, while strengthening of the elastic foundation has the reverse effect. For the P-P case, no combination resonance occurs for this system, but for the $\mathrm{C}-\mathrm{C}$ case, a combination resonance of the sum type occurs for all parameters.

\section{REFERENCES}

1 Hetenyi, M. Beams on Elastic Foundation, University of Michigan Press, Ann Arbor, (1946).

2 Clementi, F., Demeio, L., Mazzilli, C. E. N, and Lenci, $\mathrm{S}$. Nonlinear vibrations of non-uniform beams by the MTS asymptotic expansion method, Continuum Mechanics and Thermodynamics, 27 (4-5), 703-717, (2015). https://dx.doi.org/10.1007/s00161-014-0368-3

3 Chonan, S. Vibration and stability of sandwich beams with elastic bonding, Journal of Sound and Vibration, 


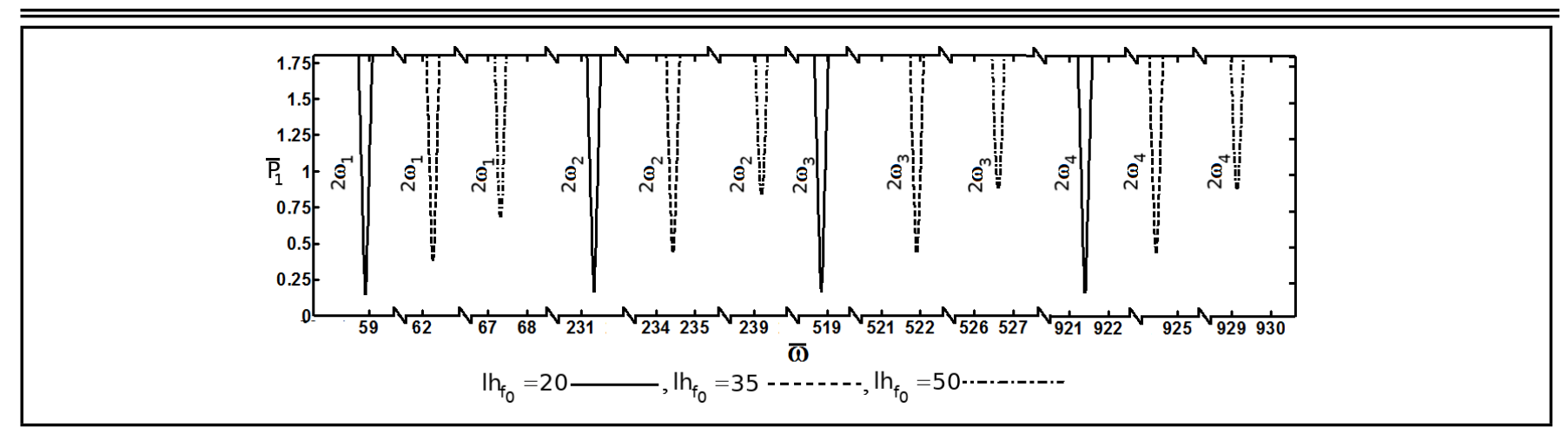

Figure 12. Effect of $l h_{f_{0}}$ on the instability zones.

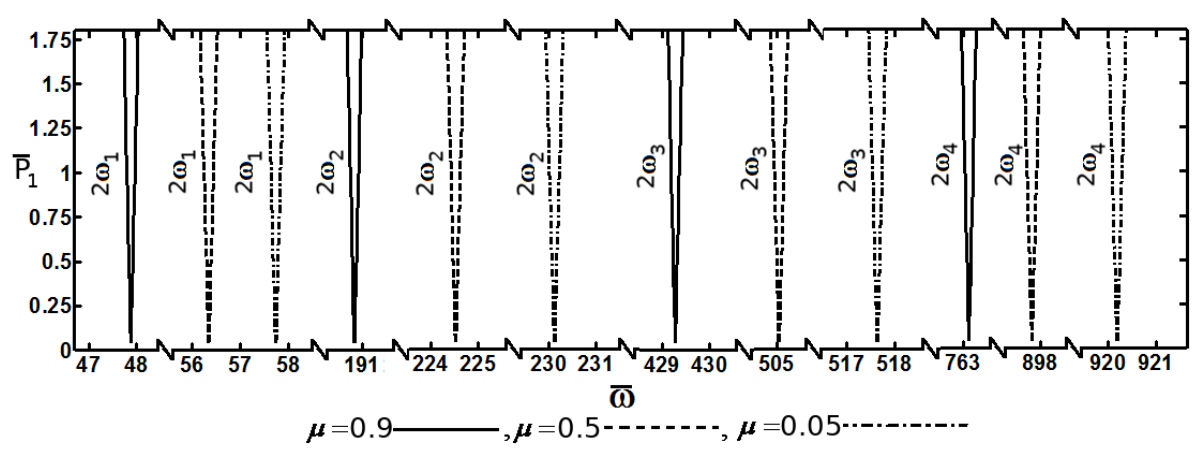

Figure 13. Effect of $\mu$ on the instability zones.

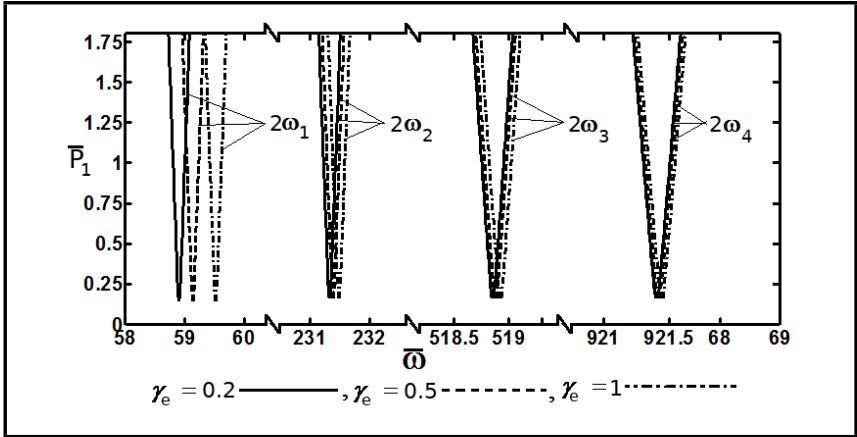

Figure 14. Effect of $\gamma_{e} \leq 1$ on the instability zones.

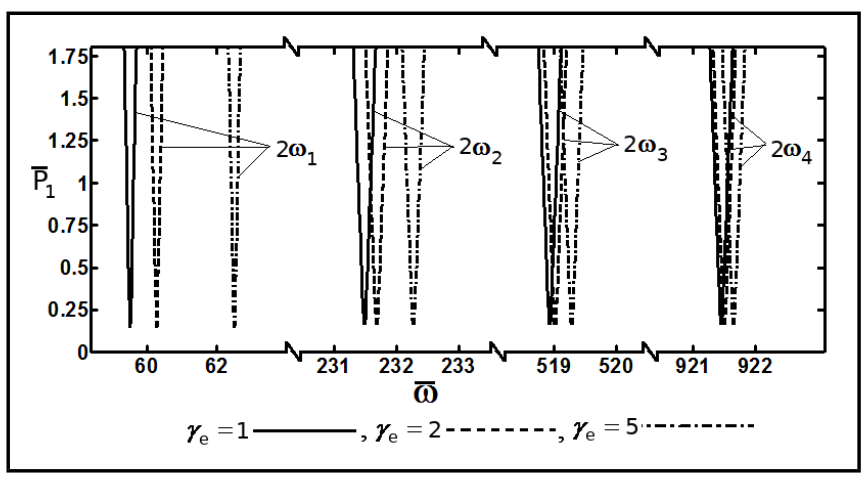

Figure 15. Effect of $\gamma_{e} \geq 1$ on the instability zones.

85 (4), 525-537, (1982). https://dx.doi.org/10.1016/0022$460 X(82) 90321-2$

4 Chonan, S. Vibration and stability of a two-layered beam with imperfect bonding, Journal of the Acoustical Society of America, 72 (1), 208-213, (1982). https://dx.doi.org/10.1121/1.387979
5 Asnani, N. T. and B. C. Nakra, B. C., Vibration analysis of multilayered beams with alternate elastic and viscoelastic layers, Journal of the Institution of Engineers (India): Mechanical Engineering Division, 50, 187-193, (1970).

6 Asnani, N. T. and Nakra, B. C., Vibration damping characteristics of multilayered beams with constrained viscoelastic layers, Journal of Engineering for Industry, 98 (3), 895901, (1976). https://dx.doi.org/10.1115/1.3439049

7 Asnani, N. T. and Nakra, B. C., Forced vibration analysis of sandwich beams with viscoelastic core, Journal of Aerospace Sciences and Technologies, 24, 288-294, (1972).

8 Caruntu, D. I., On nonlinear forced response of nonuniform beams, ASME 2008 Dynamic Systems and Control Conference, Parts A and B, 403-408, (2008). https://dx.doi.org/10.1115/DSCC2008-2157

9 Kar, R. C. and Sujata, T. Dynamic stability of a tapered symmetric sandwich beam, Computers \& Structures, 40 (6), 1441-1449, (1991). https://dx.doi.org/10.1016/00457949(91)90414-H

10 Ray, K., and Kar, R. C. Parametric instability of a sandwich beam under various boundary conditions, Computers \& Structures, 55 (5), 857-870, (1995). https://dx.doi.org/10.1016/0045-7949(94)00427-5

11 Ray, K., and Kar, R. C. Parametric instability of multilayered sandwich beams, J. Sound Vib., 193 (3), 631-644, (1996). https://dx.doi.org/10.1006/jsvi.1996.0305 


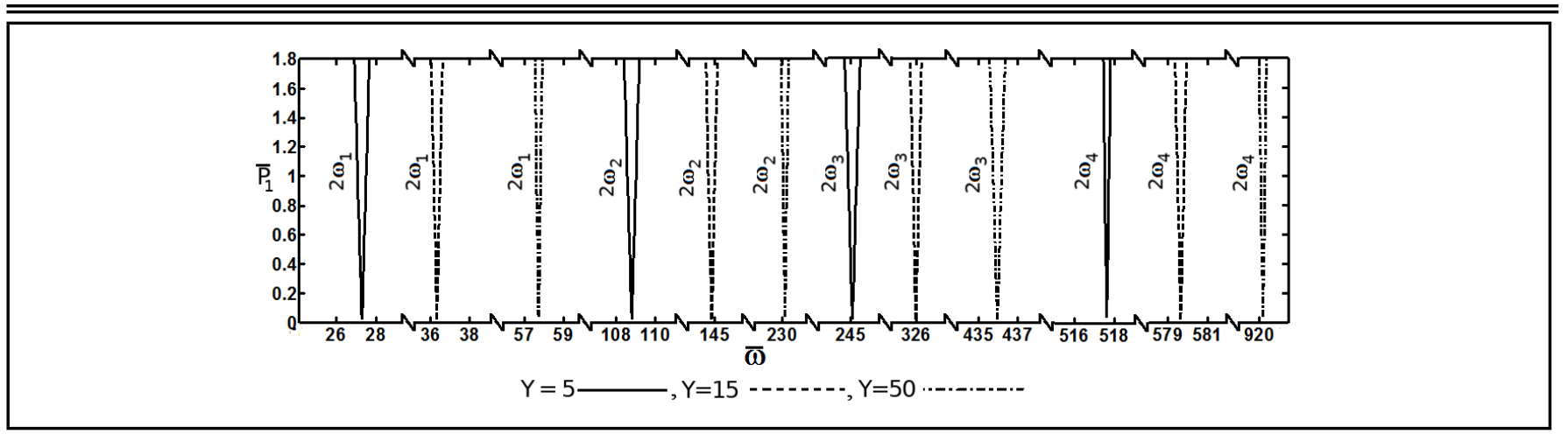

Figure 16. Effect of $Y$ on the instability zones.

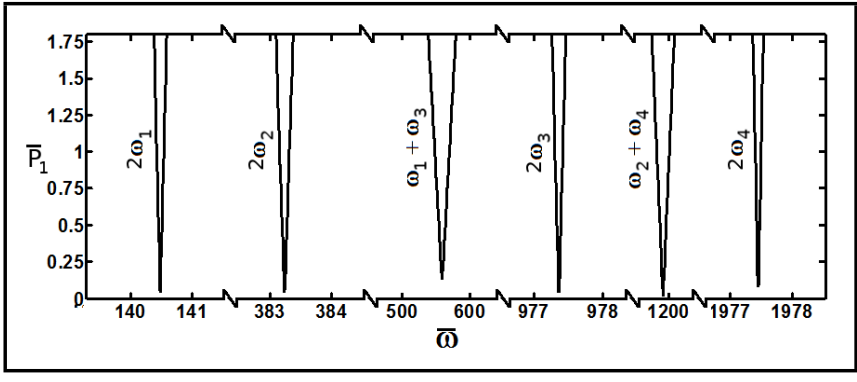

Figure 17. Stability diagrams for $g=0.1, \mu=0.05, Y=50, \beta=1.5$.

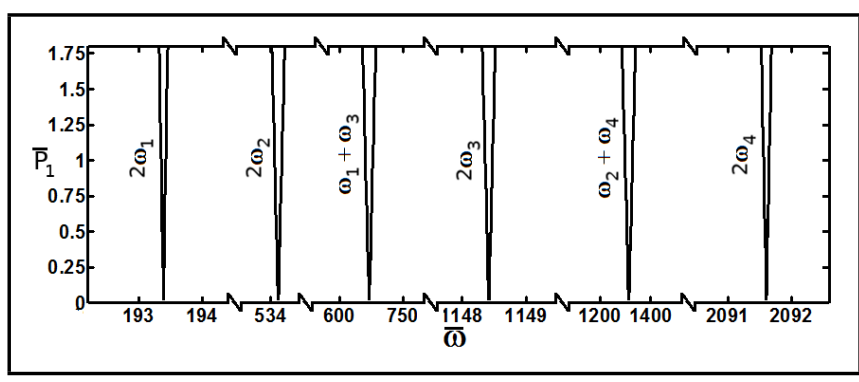

Figure 18. Stability diagrams for $g=0.1, \mu=0.05, Y=50, \beta=2.5$.

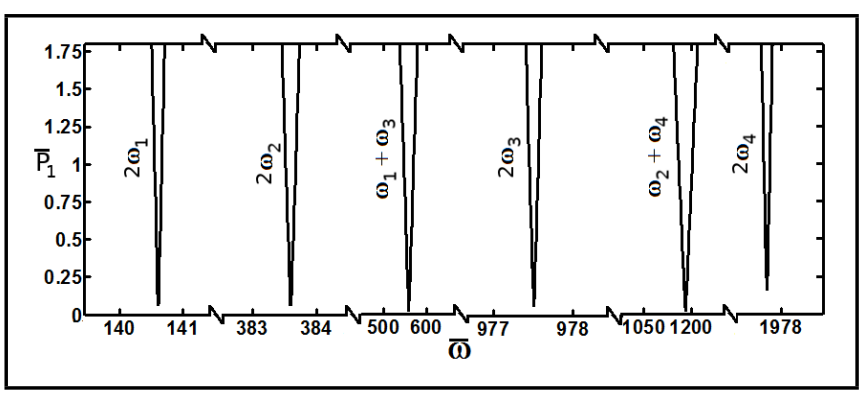

Figure 19. Stability diagrams for $g=0.1, \mu=0.05, Y=50, \delta / l=0.1$.

12 Rao, D. K. Frequency and loss factors of sandwich beams under various boundary conditions, Journal of Mechanical Engineering and Science, 20 (5), 271-282, (1978). https://dx.doi.org/10.1243/JMES_JOUR_1978_020_047_02

13 Kerwin, E. M. Jr. Damping of flexural waves by a constrained viscoelastic layer, Journal of the Acoustical Society of America, 31 (7), 952-962, (1959). https://dx.doi.org/10.1121/1.1907821

14 Saito, H. and Otomi, K. Parametric response of viscoelastically supported beams, Journal of Sound and Vibration,

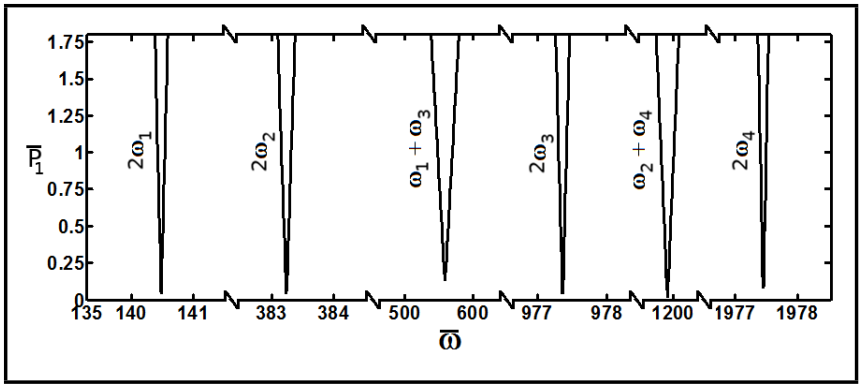

Figure 20. Stability diagrams for $g=0.1, \mu=0.05, Y=50, \delta / l=0.5$.

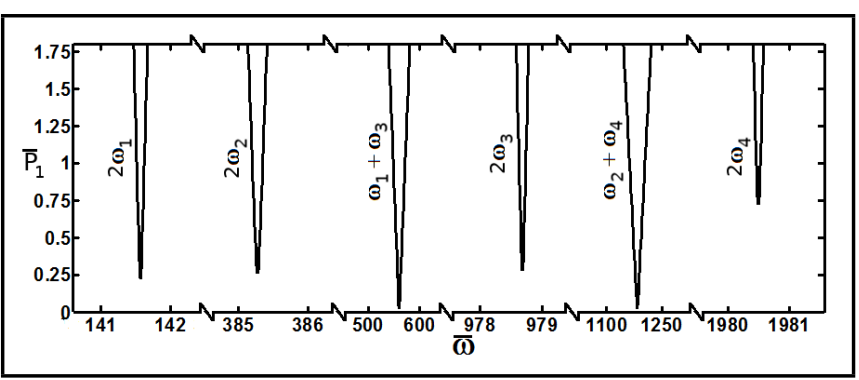

Figure 21. Stability diagrams for $g=0.1, \mu=0.05, Y=50$, $G_{2} / E_{f}=0.001$.

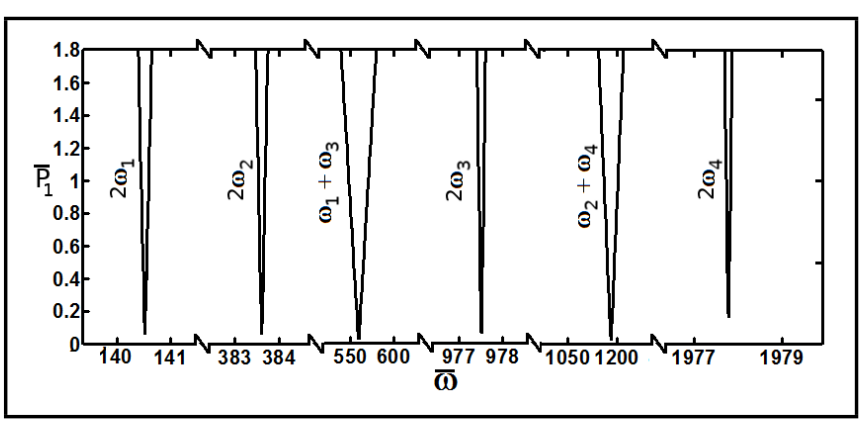

Figure 22. Stability diagrams for $g=0.1, \mu=0.05, Y=50$, $G_{2} / E_{f}=0.005$.

63 (2), 169-178, (1979). https://dx.doi.org/10.1016/0022$460 X(79) 90874-5$

15 Sato, M., Kanie, S., and Mikami, T. Mathematical analogy of a beam on elastic supports as a beam on elastic foundation, Applied Mathematical Modelling, 32 (5), 688-699, (2008). https://dx.doi.org/10.1016/j.apm.2007.02.002

16 Wang., L., Ma, J., Peng, J., and Li, L. Large amplitude vibration and parametric instability of inextensional beams on the elastic foundation, Interna- 


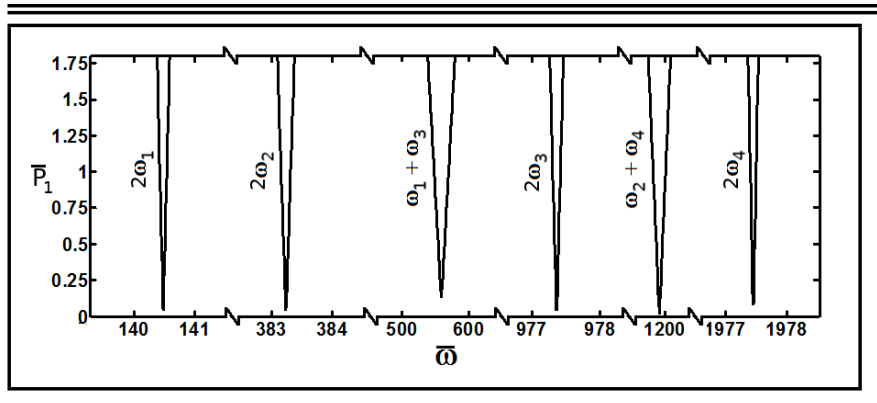

Figure 23. Stability diagrams for $g=0.1, \mu=0.05, Y=50$, $G_{S} / E_{f}=0.0005$.

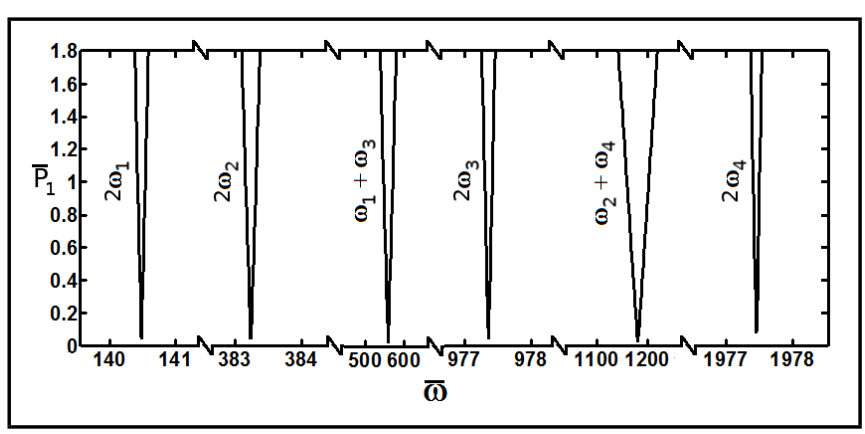

Figure 24. Stability diagrams for $g=0.1, \mu=0.05, Y=50$, $G_{S} / E_{f}=0.002$.

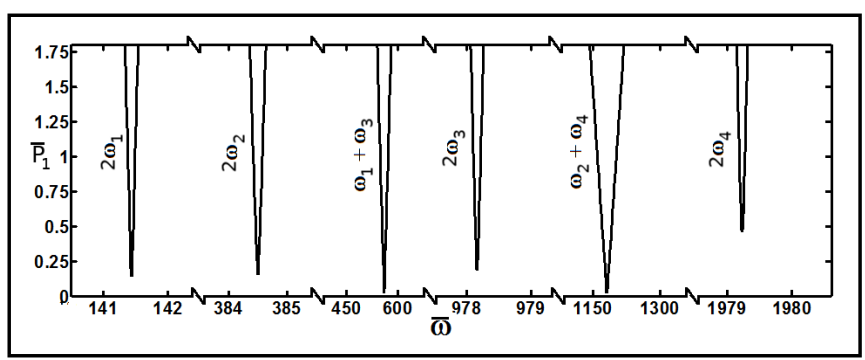

Figure 25. Stability diagrams for $g=0.1, \mu=0.05, Y=50, l h_{f_{0}}=35$.

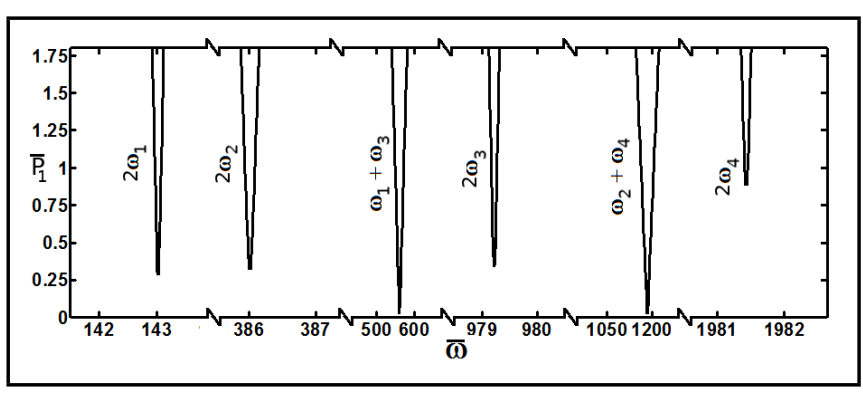

Figure 26. Stability diagrams for $g=0.1, \mu=0.05, Y=50, l h_{f_{0}}=50$.

tional Journal of Mechanical Sciences, 67, 1-9, (2013). https://dx.doi.org/10.1016/j.ijmecsci.2012.12.002

17 Wang, L., Ma, J., Zhao, Y. and Liu, Q. Refined modeling and free vibration of inextensional beams on the elastic foundation, Journal of Applied Mechanics, 80 (4), 041026041026-11, (2013). https://dx.doi.org/10.1115/1.4023032

18 Nayak, B., Dwivedy, S. K., and Murthy, K. S. R. K. Multifrequency excitation of magnetorheological elastomerbased sandwich beam with conductive skins, International Journal of Non-Linear Mechanics, 47 (5), 448-460, (2012). https://dx.doi.org/10.1016/j.ijnonlinmec.2011.08.007

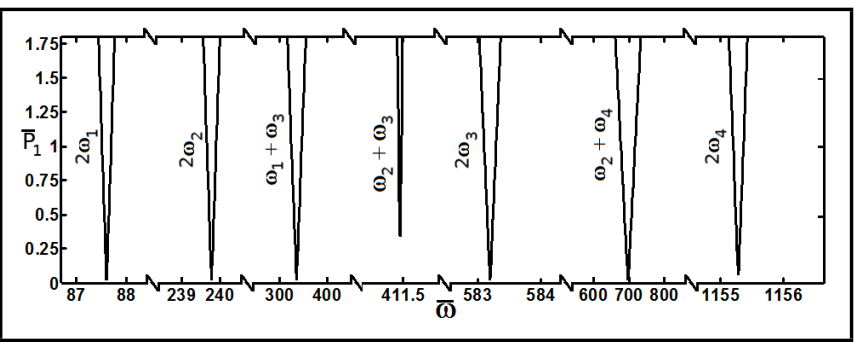

Figure 27. Stability diagrams for $g=0.1, \mu=0.05, Y=15$.

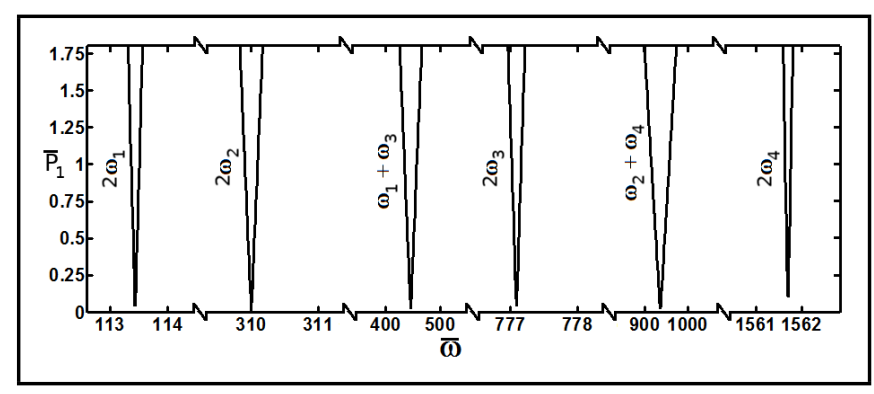

Figure 28. Stability diagrams for $g=0.1, \mu=0.05, Y=30$.

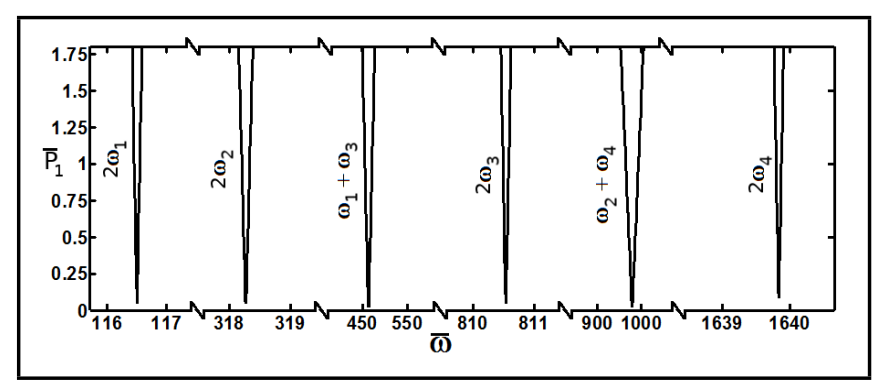

Figure 29. Stability diagrams for $g=0.1, Y=50, \mu=0.5$.

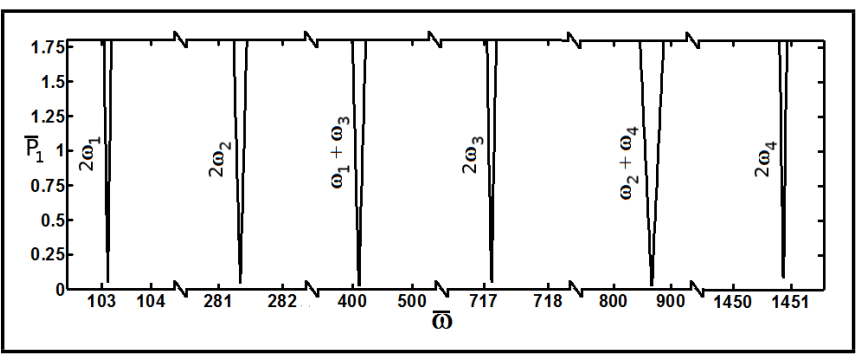

Figure 30. Stability diagrams for $g=0.1, Y=50, \mu=0.9$.

19 Nayak, B., Dwivedy, S. K., Murthy, K. S. R. K. Dynamic analysis of magnetorheological elastomer-based sandwich beam with conductive skins under various boundary conditions, Journal of Sound and Vibration, 330 (9), 1837-1859, (2011). https://dx.doi.org/10.1016/j.jsv.2010.10.041

${ }^{20}$ Lenci, S. and Clementi, F. Effects of shear stiffness, rotatory and axial inertia, and interface stiffness on free vibrations of a two-layer beam, Journal of Sound and Vibration, 331 (24), 5247-5267, (2012). https://dx.doi.org/10.1016/j.jsv.2012.07.004

${ }^{21}$ Lenci, S. and Clementi, F. On flexural vibrations of shear deformable laminated beams, ASME International Mechanical Engineering Congress and Exposition, 4, 581-590, (2012). https://dx.doi.org/10.1115/IMECE2012-86617 


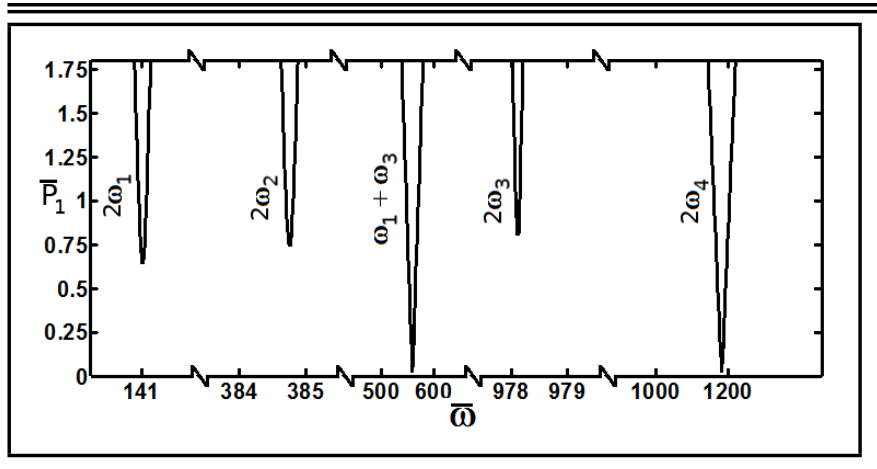

Figure 31. Stability diagrams for $g=0.1, Y=50, \mu=0.05, \eta=0.05$.

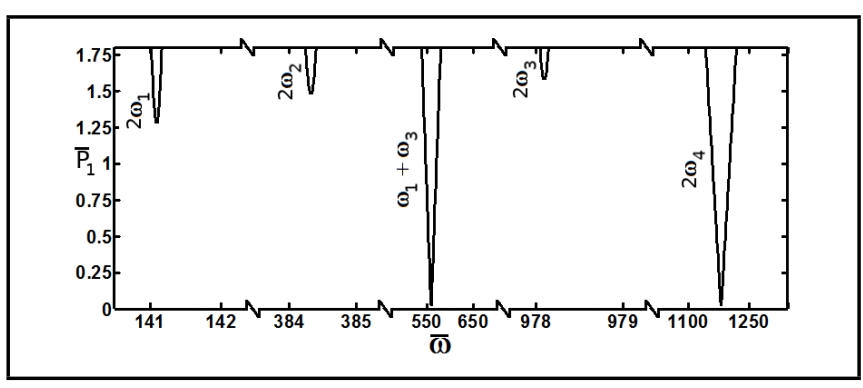

Figure 32. Stability diagrams for $g=0.1, Y=50, \mu=0.05, \eta=0.5$.

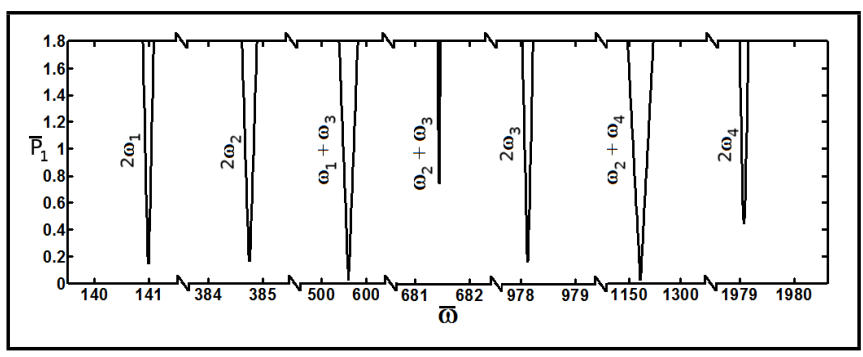

Figure 33. Stability diagrams for $g=0.1, Y=50, \mu=0.05, \gamma_{e}=0.2$.

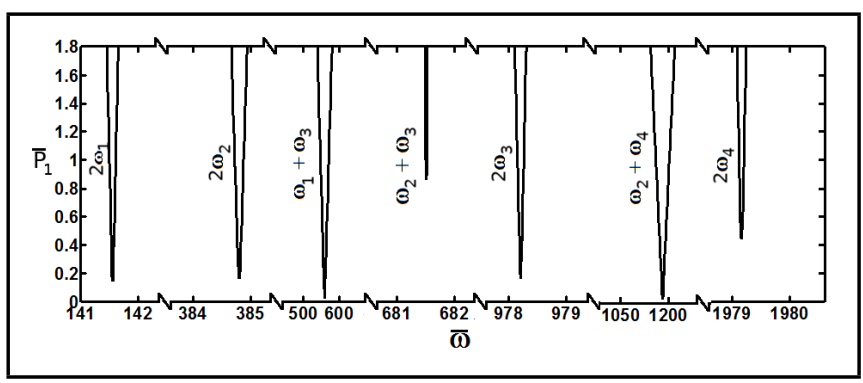

Figure 34. Stability diagrams for $g=0.1, Y=50, \mu=0.05, \gamma_{e}=2$.

22 Dash, P. R., Maharathi, B. B., and Ray, K., Dynamic stability of an asymmetric sandwich beam resting on a Pasternak foundation, Journal of Aerospace Sciences and Technologies, 62 (1), 66-75, (2010).

23 Lenci, S., Clementi, F., and Warminski, J. Nonlinear free dynamics of a two-layer composite beam with different boundary conditions, Meccanica, 50 (3), 675-688, (2015). https://dx.doi.org/10.1007/s11012-014-9945-6

24 Lenci, S., Clementi, F. and Mazzilli, C. E. N. Simple formulas for the natural frequencies of nonuniform cables and beams, International Journal of Mechanical Sciences, 77, 155-163, (2013). https://dx.doi.org/10.1016/j.ijmecsci.2013.09.028

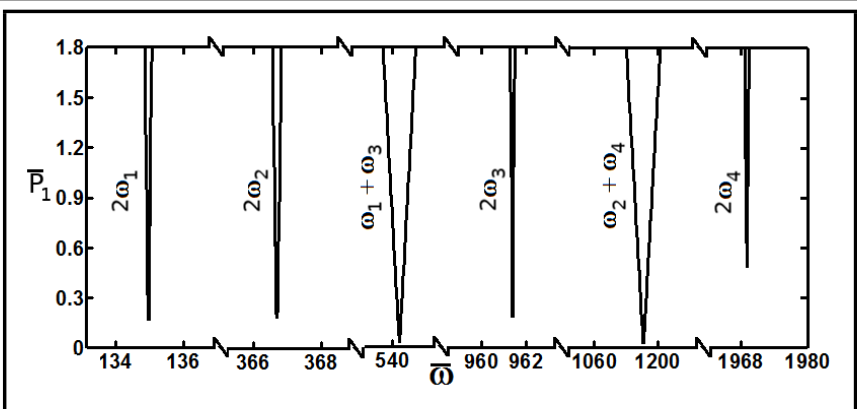

Figure 35. Stability diagrams for $g=0.1, Y=50, \mu=0.05, \alpha=0.2$.

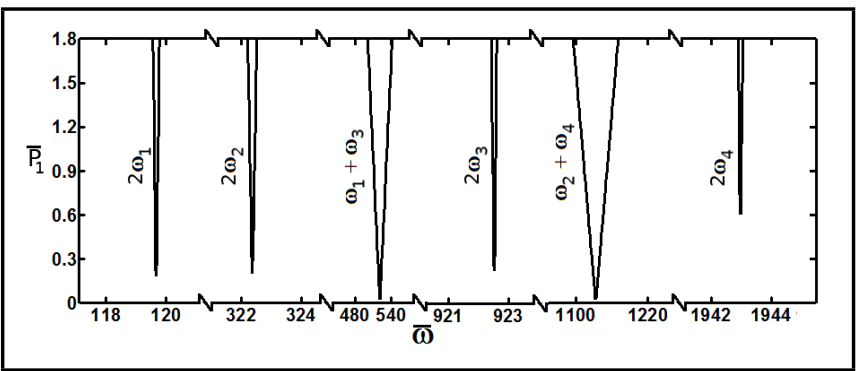

Figure 36. Stability diagrams for $g=0.1, Y=50, \mu=0.05, \alpha=0.8$.

25 Babilio, E. Dynamics of an axially functionally graded beam under axial load, European Physical Journal Special Topics, 222 (7), 1519-1539, (2013). https://dx.doi.org/10.1140/epjst/e2013-01942-8

26 Ko, C. L. Flexural behavior of a rotating sandwich tapered beam, AIAA Journal, 27 (3), 359-369, (1989). https://dx.doi.org/10.2514/3.10120

27 Rao, D. K. and Stühler, W. Frequency and loss factors of tapered symmetric sandwich beams, Journal of Applied Mechanics, 44 (3), 511-513, (1977). https://dx.doi.org/10.1115/1.3424117

28 Ahuja, R. and R. C. Duffield, R. C. Parametric instability of variable cross-section beams resting on an elastic foundation, Journal of Sound and Vibration, 39 (2), 159-174, (1975). https://dx.doi.org/10.1016/S0022-460X(75)80215$\mathrm{X}$

29 Szekrényes1, A. A special case of parametrically excited systems: Free vibration of delaminated composite beams, European Journal of Mechanics - A/Solids, 49, 82-105, (2015). https://dx.doi.org/10.1016/j.euromechsol.2014.07.003

${ }^{30}$ Leipholz, H. Stability theory: An introduction to the stability of dynamic systems and rigid bodies, John Wiley and Sons, Chichester, (1987), 2nd edition.

31 Kar, R. C. and Sujata, T. Parametric instability of Timoshenko beam with thermal gradient resting on a variable Pasternak foundation, Computers \& Structures, 36 (4), 659-665, (1990). https://dx.doi.org/10.1016/00457949(90)90081-C 